\title{
Commonalities and differences of T3SSs in rhizobia and plant pathogenic bacteria
}

\author{
Anastasia P. Tampakaki* \\ Laboratory of General and Agricultural Microbiology, Department of Crop Science, Agricultural University of Athens, Athens, Greece
}

\section{Edited by:}

Carmen R. Beuzón, University of

Málaga, Spain

\section{Reviewed by:}

Laila Pamela Partida-Martinez,

Centro de Investigaciones

Avanzadas del Instituto Politecnico

Nacional, Mexico

Rafael Rivilla, Universidad Autónoma

de Madrid, Spain

Maria Jose Soto, Consejo Superior

de Investigaciones Cientificas, Spain

\section{*Correspondence:}

Anastasia P. Tampakaki, Laboratory

of General and Agricultural

Microbiology, Department of Crop

Science, Agricultural University of

Athens, lera Odos 75, Votanikos,

11855, Athens, Greece

e-mail: tampakaki@aua.gr
Plant pathogenic bacteria and rhizobia infect higher plants albeit the interactions with their hosts are principally distinct and lead to completely different phenotypic outcomes, either pathogenic or mutualistic, respectively. Bacterial protein delivery to plant host plays an essential role in determining the phenotypic outcome of plant-bacteria interactions. The involvement of type III secretion systems (T3SSs) in mediating animal- and plant-pathogen interactions was discovered in the mid-80's and is now recognized as a multiprotein nanomachine dedicated to trans-kingdom movement of effector proteins. The discovery of T3SS in bacteria with symbiotic lifestyles broadened its role beyond virulence. In most T3SS-positive bacterial pathogens, virulence is largely dependent on functional T3SSs, while in rhizobia the system is dispensable for nodulation and can affect positively or negatively the mutualistic associations with their hosts. This review focuses on recent comparative genome analyses in plant pathogens and rhizobia that uncovered similarities and variations among T3SSs in their genetic organization, regulatory networks and type III secreted proteins and discusses the evolutionary adaptations of T3SSs and type III secreted proteins that might account for the distinguishable phenotypes and host range characteristics of plant pathogens and symbionts.

Keywords: type III secretion, plant pathogenic bacteria, rhizobia, nodulation, pili, plant-associated bacteria, translocator, atypical T3SSs

\section{INTRODUCTION}

The relationships of plants with microbes could result in different interaction outcomes, either pathogenic or mutualistic or parasitic, depending on the combination of partners. Regardless of the outcome of the association, plant-microbe interactions involve the exchange of signals between both partners. This process is highly complex and multi-layered and requires the coordination of signal sensing and regulatory networks of both partners. A common aspect of the interactions of plants with either harmful or beneficial bacteria is the recognition of microbes as invaders due to the presence of microorganism-associated molecular patterns, which results in triggering plant immune responses in order to limit microbial invasion (Boller and Felix, 2009; Zamioudis and Pieterse, 2012; Newman et al., 2013). Interestingly, microbes evolved various common mechanisms to overcome the plant immune responses and to finally establish a successful infection (Soto et al., 2006; Deakin and Broughton, 2009; Torto-Alalibo et al., 2009; Partida-Martínez and Heil, 2011; Rivas and Genin, 2011; Saeki, 2011). Despite the commonalities shared by these mechanisms, differences in the signaling molecules and networks result in the establishment either pathogenic, mutualistic or null associations.

During the last decade, numerous studies showed that microbes, including bacteria, fungi, oomycetes and nematodes deliver effector molecules either to the extracellular milieu or into the host cytoplasm to facilitate colonization. In bacteria, effector delivery occurs via diverse mechanisms such as the type III (T3SS), the type IV (T4SS), and the type VI (T6SS) secretion systems. These specialized secretion systems are thought to fine-tune the interactions of bacteria with their host partners. Of these, the T3SS has been recognized as a central player in the interaction of both pathogens and symbionts with diverse hosts. Both types of microbes exploit the T3SS to suppress or evade the plant immune system and to finally establish a successful infection.

In nowadays, the research field of type III secretion systems experiences a wave of novel insights thanks to the advances of second-generation sequencing technologies and their applications on genomics and transcriptomics. The increasing availability of whole genome sequences has revolutionized our knowledge of mechanisms that govern plant-microbe interactions. Comparative genomics and extensive genetic studies have unveiled alternative strategies used by bacteria to invade their hosts (Amadou et al., 2008; Masson-Boivin et al., 2009; Tian et al., 2012). Earlier beliefs about the specific attributes required for a particular interaction have been revised to a certain extent. For example, the absence of nod genes from the genomes of two photosynthetic Bradyrhizobia revised the assumption that nod genes are absolutely required for initiation of nodulation (Giraud et al., 2007). Similarly, the earlier belief that the T3SS was exclusive attribute of pathogenic bacteria was abandoned when more bacterial genome sequences became available. Moreover, the flood of sequence data has unveiled the presence of more and non-canonical T3SSs in a large number of bacteria with various lifestyles thus providing the opportunity and the challenge to gain a better understanding of the T3SS's complexity and the mechanisms underlying plant-microbe interactions and beyond.

Comparison of different genomes between phytopathogenic bacteria and rhizobia has highlighted many similarities and 
variations of their T3SSs. Despite the similarities among different members of plant-associated bacteria, important genetic differences also exist. This review provides a synopsis of our current understanding of the T3SSs found in rhizobia and plant pathogenic bacteria.

\section{GENERAL DESCRIPTION OF T3SS GENE CLUSTERS IN PHYTOPATHOGENIC BACTERIA AND RHIZOBIAL SPECIES}

So far, most of the T3SS gene clusters of phytopathogenic bacteria have been divided into two groups, designated as $h r p / h r c l$ and $h r p / h r c 2$ based on gene composition, arrangement, and transcriptional regulation but, depending on the strain, they either lack some genes or carry additional ones (Alfano and Collmer, 1997; Tampakaki et al., 2010). However, the availability of an increasing number of bacterial genomes has unveiled the presence of T3SSs with different genetic organization and phylogeny that do not fall into the abovementioned groups (Figure 1, Table 1). These novel T3SSs are discussed in detail in the following sections. The hrp/hrcl group contains clusters from species of Pseudomonas and Erwinia, while the hrp/hrc2 occurs in species from Xanthomonas, Ralstonia, Acidovorax, and Burkholderia. All T3SSs are clustered within regions of ca. $22-50 \mathrm{~kb}$ in pathogenicity islands (PAIs), mainly located on the chromosome and in some cases on plasmids (e.g., Ralstonia solanacearum and Pantoea agglomerans pv. gypsophilae and pv. betae). The genes in both groups are organized in operons and the number of ORFs ranges from 24 (Xanthomonas pathovars) to 27 (Pseudomonas pathovars). All contain genes encoding the structural components of the secretion apparatus and secreted proteins as well as less conserved proteins with accessory roles in the structure and regulation of the secretion machinery. A unifying nomenclature has been proposed to describe the T3SS core components with the prefix secretion and cellular translocation (sct), followed by the suffixes used in the Yersinia Ysc system (Hueck, 1998; Abby and Rocha, 2012). Common to all functional T3SSs are proteins belonging to nine families (SctC, SctJ, SctN, SctQ, SctR, SctS, SctT, SctU, $\mathrm{SctV}$ ). The flanking regions of T3SS clusters usually carry type III effector (T3E) genes but their gene content and structure differ among species/pathovars (Tampakaki et al., 2010). However, most effector genes are scattered throughout the genomes and are not physically linked to the T3SS gene clusters (Lindeberg et al., 2008). One common feature shared by most Pseudomonas syringae pathovars is the tripartite gene structure of their $h r p / h r c$ clusters (Alfano et al., 2000). They are composed of an exchangeable effector locus (EEL), a cluster of $h r p / h r c$ genes, and a conserved effector locus (CEL). The EEL is variable among pathovars, rich in effector-coding genes and contains many sequences related to mobile genetic elements. The CEL encodes three T3Es present in all characterized strains (Charity et al., 2003; Deng et al., 2003).

The first evidence for the presence and functionality of T3SS in rhizobia originated from the sequencing of plasmid pNGR234a of Sinorhizobium fredii NGR234 (Viprey et al., 1998). Sequencing of genomes and plasmids in other rhizobial strains later revealed that T3SSs are distributed in several, but not all, rhizobial species (Kaneko et al., 2000, 2002; Göttfert et al., 2001; Krause et al., 2002; Krishnan et al., 2003; de Lyra Mdo et al., 2006). Similar to phytopathogenic bacteria, genes for T3SSs found so far in rhizobia are clustered within regions of $30-47 \mathrm{~kb}$ in symbiotic islands located either on the chromosome or on symbiotic plasmids (pSym), on which nodulation and nitrogen fixation genes also are located (Freiberg et al., 1997; Viprey et al., 1998; Kaneko et al., 2000; Göttfert et al., 2001; Marie et al., 2001; Krishnan et al., 2003; de Lyra Mdo et al., 2006). The genes encoding the core components of rhizobial T3SS are called rhc (Rhizobium conserved), while the secreted proteins are designated Nops (nodulation outer proteins) (Viprey et al., 1998; Marie et al., 2001). The rhizobial T3SS gene clusters are designated tts (type three secretion) and constitute a distinct family, called Rhc family (Rhizobiales family) based on phylogenetic analyses of T3S core components (Troisfontaines and Cornelis, 2005). Most of the rhizobial T3SS genes are expressed in response to plant-made flavonoids which also induce genes relevant to symbiosis (e.g., nodulation genes). Their promoter regions harbor a regulatory motif known as tts box, a binding site for the transcriptional activator TtsI whose production is flavonoid dependent. To date, functional T3SSs have been reported in S. fredii NGR234 (Viprey et al., 1998), Bradyrhizobium japonicum USDA110 (Krause et al., 2002), S. fredii USDA257 (Krishnan et al., 2003), S. fredii HH103 (de Lyra Mdo et al., 2006), Bradyrhizobium elkanii (Okazaki et al., 2009), and Mesorhizobium loti MAFF303099 (Okazaki et al., 2010).

In contrast to biotrophic phytopathogenic bacteria, the T3SSs are not essential for rhizobia to interact with plant hosts since several rhizobia lacking a T3SS are still able to nodulate legumes. Nevertheless, functional studies in T3SS-containing rhizobia have demonstrated the contribution of T3SS in nodule formation on several legume species. Moreover, it is of great interest the discovery of $R$ genes that control symbiotic specificity at genotype level which implies that common recognition principles govern both plant-pathogen and legume-rhizobium interactions (Yang et al., 2010a).

Although substantial advances have been made in the structure, function and regulation of T3SSs in phytopathogenic bacteria, even less is known about T3SSs in rhizobia. In order to delineate the similarities and differences between T3SSs of phytopathogenic bacteria and rhizobia, it was advisable to present here the various types of rhizobial T3SSs in more detail since no overview articles in the literature are currently available for the reader.

\section{RHIZOBIAL T3SS GENE CLUSTERS}

The Rhc T3SS family is further subdivided into four subgroups based on a phylogenetic analysis of T3SS core proteins (Gazi et al., 2012). Subgroup Rhc-I contains members of S. fredii, M. loti, and B. japonicum, Rhc-II involves the second T3SS of S. fredii NGR234 located on plasmid pNGR234b and T3SSs from various $P$. syringae pathovars, and Rhc-III is represented by the T3SSs of R. etli strains (Figure 2, Table 2). A distinct group designated $\beta$ Rhc forms the $\beta$-rhizobium Cupriavidus taiwanensis. Despite the categorization of $t$ ts clusters in Rhc subgroups, members belonging to the subgroup Rhc-I show subtle differences in respect to their physical gene organization and gene content. So far, only the $t$ ts clusters of Rhc-I group have been shown to be functional and to affect the nodulation process. Moreover, the operon structure presented here is based on the literature as was deduced from 


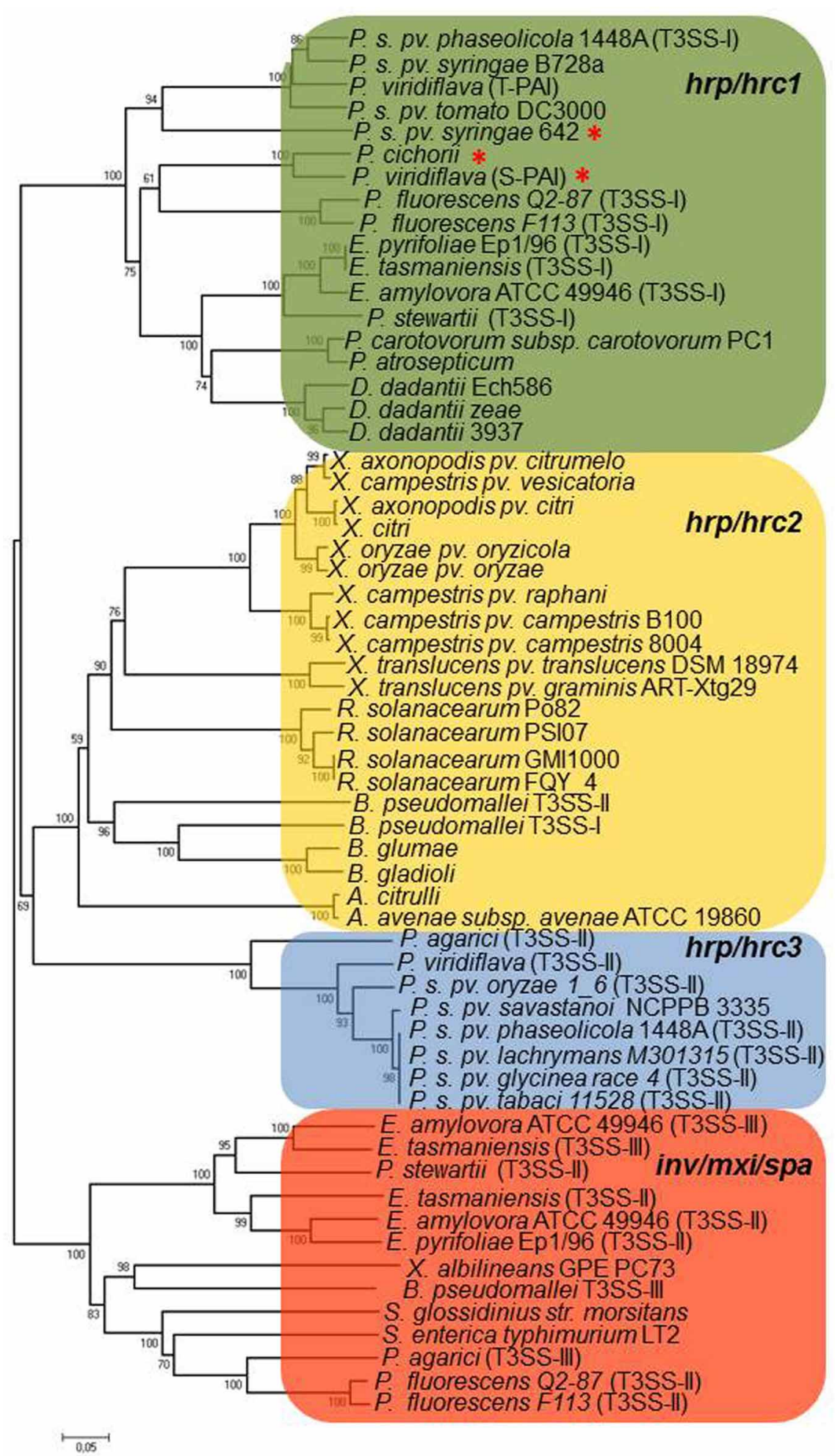

FIGURE 1 | Neighbor-joining phylogenies of SctU proteins from representative phytopathogenic and plant-associated bacteria. The red asterisk denotes atypical hrp/hrc gene clusters, as discussed in the text. The bacteria belonging to $h r p / h r c 3$ group also harbor a $h r p / h r c 1$ gene cluster which is not represented in the tree, in all cases (see Table 1). The evolutionary distances were estimated using the p-distance method and are in the units of the number of amino acid differences per site. Numbers to the left of the branches are bootstrap values for 1000 replications. Bootstrap values greater than $50 \%$ are shown, and the scale bar represents the number of substitutions per site. Branch lengths are proportional to the amount of evolutionary change. Evolutionary analyses were conducted in MEGA6 (Tamura et al., 2013). 
Table 1 | Distribution of various T3SS types in phytopathogenic and plant-associated bacteria containing atypical T3SSs.

\begin{tabular}{|c|c|c|c|c|}
\hline & Hrp/Hrc1-2 & Inv/Mxi/Spa & Hrp/Hrc3 & References \\
\hline \multicolumn{5}{|l|}{ PHYTOPATHOGENIC BACTERIA } \\
\hline $\begin{array}{l}\text { Psph 1448A; Psph 1644R; Psor 1_6; Psta } \\
\text { ATCC11528; Psae NCPPB 3681; Psae } \\
\text { 2250; Psae 0893_23; Psgly B076; Psgly } \\
\text { 4; Psave ISPaVe013; Psave ISPaVe037 } \\
\text {;Psave BP631; Psla M301315; Psact } \\
\text { M302091; Psmo M302280PT; PsCit; Psav } \\
\text { NCPPB 3335; Pvir UASWS0038 }\end{array}$ & & & & $\begin{array}{l}\text { Joardar et al., 2005; Reinhardt et al., 2009; } \\
\text { Studholme et al., 2009; Green et al., 2010; } \\
\text { Rodríguez-Palenzuela et al., 2010; Baltrus } \\
\text { et al., 2011; Qi et al., 2011; O'Brien et al., } \\
\text { 2012; Lefort et al., } 2013\end{array}$ \\
\hline Eam CFBP 1430; Eam Ea273 (ATCC49946) & & & & $\begin{array}{l}\text { Bocsanczy et al., 2008; Sebaihia et al., 2010; } \\
\text { Smits et al., 2010b }\end{array}$ \\
\hline Epyr Ep16/96; Epyr Ep1/96 & & $\$ 8080800$ & & Kube et al., 2010; Smits et al., 2010a \\
\hline Eam 321; Pstew subsp. stewartii & & & & Oh and Beer, 2005; Correa et al., 2012 \\
\hline X. albilineans GPE PC73 & & & & Pieretti et al., 2009; Marguerettaz et al., 2011 \\
\hline X. axonopodis pv. phaseoli & & & & Alavi et al., 2008; Marguerettaz et al., 2011 \\
\hline \multicolumn{5}{|c|}{ NON-PHYTOPATHOGENIC BACTERIA ISOLATED FROM PLANT HABITATS } \\
\hline Eta Et1/99 & & $x \times x$ & & Kube et al., 2008 \\
\hline Pfl Q2-87; Pfl F113 & & & & $\begin{array}{l}\text { Loper et al., 2012; Redondo-Nieto et al., 2012; } \\
\text { Barret et al., } 2013\end{array}$ \\
\hline $\begin{array}{l}\text { Pfl HK44; Pfus UPB0736; Pfus CB98818; } \\
\text { Pseudomonas sp. GM49 }\end{array}$ & & & & $\begin{array}{l}\text { Chauhan et al., 2011; Brown et al., 2012; Patel } \\
\text { et al., 2012; Xie et al., 2012; Barret et al., } 2013\end{array}$ \\
\hline $\begin{array}{l}\text { Pfl SBW25, Pfl WH6; Pfl R81; Pfl SS101; } \\
\text { Pfl A506; Psyn BG33R }\end{array}$ & & $\$ 8 \infty 8 \infty \infty 8$ & & $\begin{array}{l}\text { Preston et al., 2001; Silby et al., 2009; Kimbrel } \\
\text { et al., 2010; Loper et al., 2012; Mathimaran } \\
\text { et al., 2012; Barret et al., } 2013\end{array}$ \\
\hline PfI NZ052; Ptol PMS117 & & $\$ 8080800$ & & Barret et al., 2013 \\
\hline Pfl NZ007 & & $\$ 8 \infty 8 \infty 8 \infty$ & & Barret et al., 2013 \\
\hline Pput B001; Pput UW4 & & & & $\begin{array}{l}\text { Park et al., 2011; Barret et al., 2013; Duan } \\
\text { et al., } 2013\end{array}$ \\
\hline P. agarici NCPPB 2289 & & & & Barret et al., 2013 \\
\hline
\end{tabular}

Abbreviations: B. Burkholderia; E., Erwinia; Eam, E. amylovora; Epyr, E. pyrifoliae; Eta, Erwinia tasmaniensis; P., Pseudomonas; Pfl, P. fluorescens; Pfus, P. fuscov-

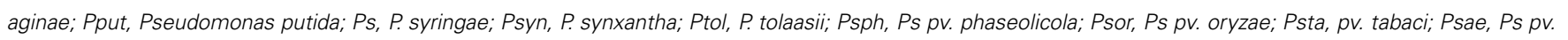

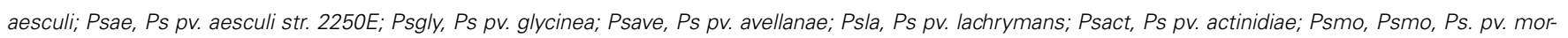

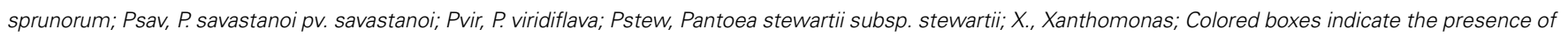

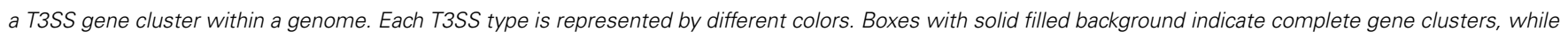

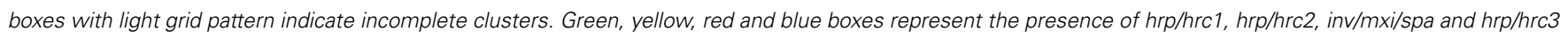

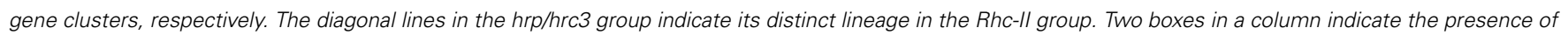
two T3SS gene clusters.

the presence of the $t$ ts or other motifs or the flavonoid-dependent induction of $t$ ts-containing promoters analyzed in many cases by transcriptional fusion reporters.

\section{Rhc-I GENE CLUSTERS}

In general, the genes encoding the T3SS core components of Rhc-I subgroup are organized, based on gene architecture, in three distinct regions, a central one (region I) and two regions (II and III), whose position in relation to the central one is variable depending on the species (Figure 3). The central region is the biggest one and contains most of the genes coding for core T3S components in the transcriptional order nopB, rhcJ, nopU, rhcL, nopZ, rhcN rhcQ, $r h c R, r h c S$, $r h c T, r h c U$. These genes possibly constitute an operon since a $t$ ts box is upstream of nopB (Perret et al., 2003; Marie et al., 2004; Wassem et al., 2008). The central region is highly conserved both in gene content and organization in all rhizobial species containing functional T3SSs. In addition, upstream of $n o p B$ is $r h c C 1$ in the opposite direction and without an obvious tts box in its upstream region. Despite the absence of known consensus promoter element motifs, such as $t$ ts boxes, upstream of some genes, this cannot rule out their TtsI- or flavonoid-dependent expression.

The regions II and III display variability both in gene content and organization and are divergently oriented in Rhc-I tts clusters. In M. loti and S. fredii strains, regions II and III are located downstream of $r h c C 1$ and $r c h U$, respectively, while in Bradyrhizobia are vice versa. Region II harbors the genes $t t s I, r h c C 2$ and $y 4 x K$ coding for a putative lipoprotein (Viprey et al., 1998; Marie et al., 


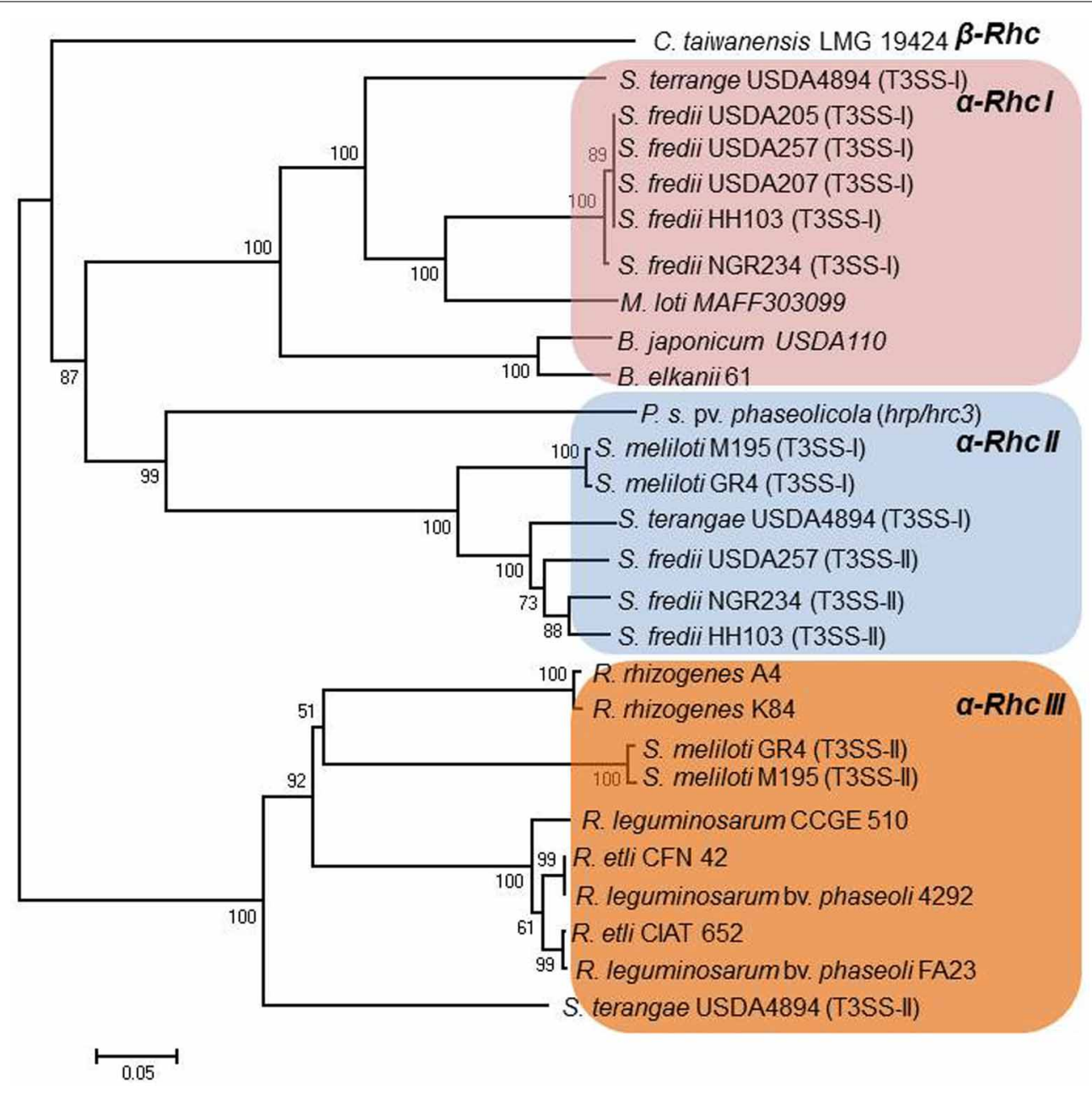

FIGURE 2 | Neighbor-joining phylogenies of SctU proteins from rhizobia. The evolutionary distances were estimated using the p-distance method and are in the units of the number of amino acid differences per site. Numbers to the left of the branches are bootstrap values for 1000 replications. Bootstrap values greater than $50 \%$ are shown, and the scale bar represents the number of substitutions per site. Branch lengths are proportional to the amount of evolutionary change. Evolutionary analyses were conducted in MEGA6 (Tamura et al., 2013).
2004). The $t$ tsI (formerly $y 4 x I$ ) is preceded by a nod box and encodes the transcriptional regulator of T3SS genes in rhizobia (Viprey et al., 1998; Krause et al., 2002; Marie et al., 2003, 2004; López-Baena et al., 2008; Sánchez et al., 2009). Region III contains a unit with the genes nopC, nopA, $r h c D, r h c V$, and $y 4 y S$ which may constitute an operon because a tts box is only present upstream of nopA and the intergenic region between nopA and $r h c D$ does not contain other discernible transcriptional motifs (Krause et al., 2002).

The tts clusters of $S$. fredii NGR234, USDA257, and HH103 have identical genetic organization, high nucleotide sequence conservation (98-99\%) even in the intergenic regions, while the protein sequence similarities range from 94 to $100 \%$. In contrast, the corresponding protein similarities in M. loti MAFF303099 ( $M$. loti) and B. japonicum USDA110 (Bja USDA110) range between 63-95\% and 41-83\%, respectively (Krishnan et al., 2003; de Lyra Mdo et al., 2006). Although, tts clusters belonging to Rhc-I subgroup share similar gene arrangement, minor diversifications exist due to the presence or absence of some genes in regions II and III (Figure 3).

\section{DIVERSIFICATIONS WITHIN RhC-I GENE CLUSTERS}

In $S$. fredii strains, the region between nopX and nopL carries a curious group of genes: $y 4 y B, y 4 y A, y 4 x P, y 4 x O, y 4 x N$, and y4xM, (Perret et al., 1999; Krishnan et al., 2003; Weidner et al., 2012), which is absent in M. loti, Bja USDA 110, and B. elkanii (Figure 3). Although the relation of these genes with the T3SS is not yet known, several findings indicate that this gene cluster may be co-regulated with nopX based on the following indications: (i) absence of a $t$ ts box in the upstream region of $y 4 y B$, (ii) no transcriptional termination signals are present in the intergenic region lying between nopX and $y 4 y B$, and (iii) expression of $y 4 x P$ is flavonoid-dependent (Perret et al., 1999; Streit et al., 2004; Lorio et al., 2006). The role of these genes remains enigmatic since mutations in three of the ORFs $(y 4 y A, y 4 y B$, and $y 4 x P)$ did not affect the production and secretion of Nops (Jiang and Krishnan, 
Table 2 | Distribution of Rhc-T3SS subgroups in rhizobia.

\begin{tabular}{|c|c|c|c|c|c|}
\hline & Rhc-I & Rhc-II & Rhc-III & $\beta$-Rhc & References \\
\hline $\begin{array}{l}\text { B. japonicum USDA110; B. elkanii USDA61; } \\
\text { B. elkanii 587; M. loti MAFF303099 }\end{array}$ & & & & & $\begin{array}{l}\text { Kaneko et al., 2000, 2002; Okazaki et al., 2009; } \\
\text { de Souza et al., } 2012\end{array}$ \\
\hline Sfr NGR234； Sfr USDA257； Sfr HH103 & & & & & $\begin{array}{l}\text { Kovács et al., 1995; Viprey et al., 1998; de Lyra } \\
\text { Mdo et al., 2006; Schmeisser et al., 2009; } \\
\text { Schuldes et al., 2012; Weidner et al., 2012; } \\
\text { Sugawara et al., } 2013\end{array}$ \\
\hline Smel KH12g; Smel KH48e; Smel M30; & & & & & Sugawara et al., 2013 \\
\hline
\end{tabular}

Smel M210; Smel M243; Smel M249; Smel

M268; Smel T094; S. saheli USDA4893

Smel GR4; Smel M195

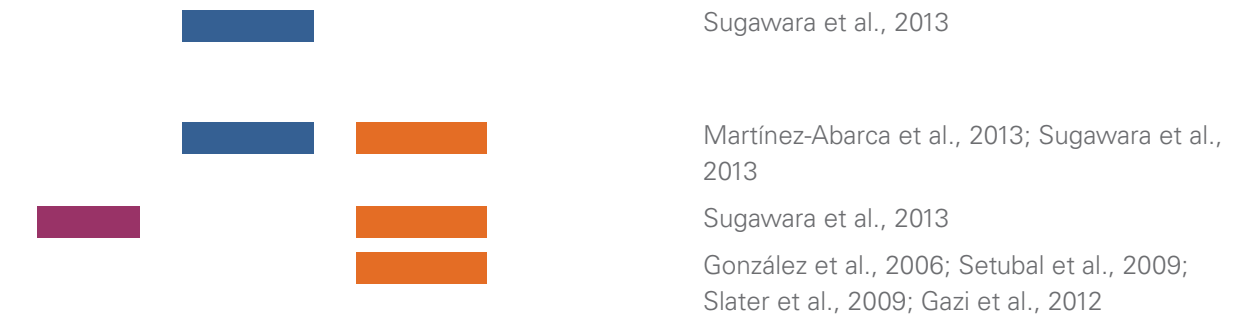

Martínez-Abarca et al., 2013; Sugawara et al., 2013

S. terrange USDA4894

R. etli CFN42; R. etli CIAT652; Rleg bv. phaseoli 4292; Rleg bv. phaseoli FA23;

Rleg bv. CCGE 510; Rrhi A4, RrhiK84

C. taiwanensis LMG 19424

Abbreviations: S., Sinorhizobium; M., Mesorhizobium; B., Bradyrhizobium, R., Rhizobium; Sfr, S. fredii; Smel, S. meliloti; Rleg, R. leguminosarum; Rrhi, R. rhizogenes; C., Cupriavidus; Colored boxes represent the presence of a T3SS gene cluster within a genome and the different colors correspond to the various Rhc subgroups.

2000; Lorio et al., 2006). Additionally, $y 4 x P$ codes for a cysteine synthase, a pivotal enzyme in sulfur assimilation and despite its location in the T3SS locus, the $y 4 x P$ product is not a type III secreted protein. Interestingly, inactivation of $y 4 x P$ in USDA191 enhanced the ability of the mutant to nodulate "McCall" soybean (Lorio et al., 2006). The presence of this gene cluster in the midst of T3SSs in S. fredii strains and in the plant pathogenic bacterium Erwinia carotovora suggests that they might originate from horizontal transfer from other bacteria (Streit et al., 2004). In $M$. loti, the T3E genes, nopP (formerly $y 4 y P$ ) and nopL (formerly $y 4 x L$ ) are missing. Homologs of nopP and nopL genes are also absent from phytopathogenic bacteria and are considered as rhizobial-specific (Bartsev et al., 2003, 2004; Ausmees et al., 2004).

The $t$ ts cluster of Bja USDA 110 displays more notable differences in comparison with those of S. fredii and M. loti strains. A distinct feature of the Bja tts cluster is the presence of several ORFs that are absent in other rhizobial species. Firstly, the region II encompasses two additional ORFs upstream of the $t$ tsI (Figure 3). One is a putative T3E gene, called nopAM (Kimbrel et al., 2013) and the other (bll1845) is predicted to encode an unknown protein. The nod box does not reside upstream of ttsI, as in other rhizobial species, but upstream of bll1845 (Krause et al., 2002). In addition, region II lacks nopX and no homolog is present in the rest of the Bja genome (Göttfert et al., 2001), while unique putative T3E genes are located in, such as nopAR (Yang et al., 2010b; Kimbrel et al., 2013) and bsr1831 (Zehner et al., 2008). This region is also rich in transposases and mobile elements suggesting that may be the gene content has resulted from gene rearrangements. Similar to region II, region III contains several ORFs that might be unique in Bja USDA 110, while the putative operon containing the genes for $r h c D$ and $r h c V$ is slightly different in gene content. A nopL-like gene is located downstream of $r h c C 1$ and is predicted to encode a protein of smaller size (167 aa) in comparison to that from $S$. fredii strains
(338 aa) (Krishnan et al., 2003; Ausmees et al., 2004; Rodrigues et al., 2007). An ORF annotated as bsl1808 coding for a hypothetical protein of 67 aa is located downstream of the nopL-like gene. However, an ORF (annotated as id211) coding for a putative 91 aa polypeptide has been identified within this region (Göttfert et al., 2001). The id211 is supposed to be the homolog of nopC (Deakin et al., 2005), for which no annotation has been reported so far in Bja USDA 110. Moreover, a $t$ ts box is present 83 bp upstream of $b s l 1808$ and overlaps with the translation start codon of the putative id211 (Zehner et al., 2008). Future studies are needed to clarify this uncertainty. In region III, three unique genes are present. The first is the nopE1 (blr1806) coding for a characterized T3E protein (Wenzel et al., 2010; Schirrmeister et al., 2011), an ORF (bll1805) coding for a hypothetical protein, but without an obvious $t$ ts box in its upstream region and nopH (blr1804) coding for a putative T3E protein (Hempel et al., 2009; Kimbrel et al., 2013). Downstream of nopH is located a nopA homolog (Krause et al., 2002; Marie et al., 2003), which is not yet annotated in the NCBI database.

\section{Rhc-II GENE CLUSTERS}

The $t$ ts clusters of the Rhc-II group are so far found only in Sinorhizobia (Table 2), are lacking the typical regulatory elements of Rhc-I group gene clusters and their role is yet unknown. Several Sinorhizobial species carry a functionl T3SS belonging to Rhc-I group and a second one belonging to Rhc-II group. In S. fredii NGR234, the T3SS located on the symbiotic plasmid pNGR234a (T3SS-I) affects nodulation in many hosts (Deakin and Broughton, 2009), while a second one (T3SS-II) resides on plasmid pNGR234b (Schmeisser et al., 2009). The latter contains 22 genes (NGR_b22800 to NGR_b23010) with twelve of them encode conserved T3SS components suggesting that it might be functional (Figure 4). However, neither nod nor tts boxes were detected in the promoter regions of these genes and the 


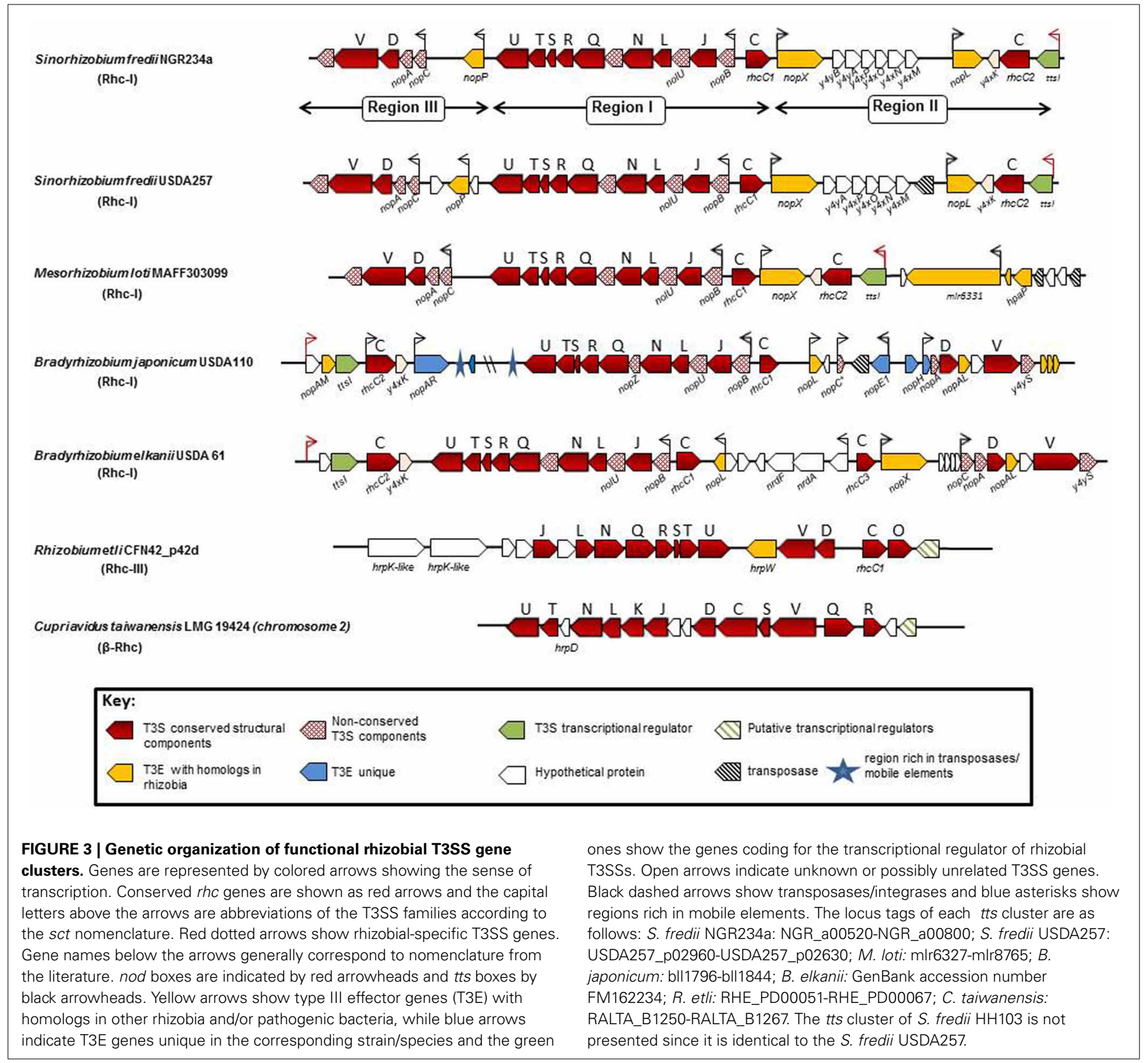

transcriptional control of the major operon of the T3SS-II cluster is weak and independent of flavonoids and/or the presence of a functional TtsI suggesting that different regulatory elements may control this T3SS locus (Bakkou and Perret, 2008; Schmeisser et al., 2009). In addition, a non-polar mutant lacking the region between rhcC1-rhcN (NGR_b22890-NGR_b22950) did not significantly affect the nodulation on several hosts (Bakkou and Perret, 2008; Schmeisser et al., 2009). Interestingly, a recent transcriptomic analysis (RNA-sec) of NGR234 bacteroids in morphologically distinct nodules of two legume hosts (Vigna unguiculata and Leucaena leucocephala) revealed that several T3SS-I locus genes were differentially expressed, while nopP, nopX and nopL were specifically upregulated in L. eucocephala nodules. Notably, T3SS-II locus genes were also upregulated, although the fold of induction was much higher in $V$. unguiculata bacteroids. In particular, all T3SS-II genes (NGR_b22800-NGR_b23010) or 8 out of 22 were significantly upregulated in bacteroids from indeterminate $L$. leucocephala and determinate $V$. unguiculata nodules, respectively, compared to the free-living bacteria (Li et al., 2013). It is worth noting that inactivation of T3SS-I did not affect the nodulation of L. leucocephala and V. unguiculata (Viprey et al., 1998). In light of these findings, T3SS-II seems to be functional depending either on the host or even the nodule type. Future studies are needed to shed light on the possible role of T3SS-II during nodulation in different plant hosts.

Similarly, S. fredii HH103 carries two T3SSs, one on the symbiotic plasmid pSfrHH103d (T3SS-I) which is functional (de Lyra Mdo et al., 2006; López-Baena et al., 2009) and a second one on 


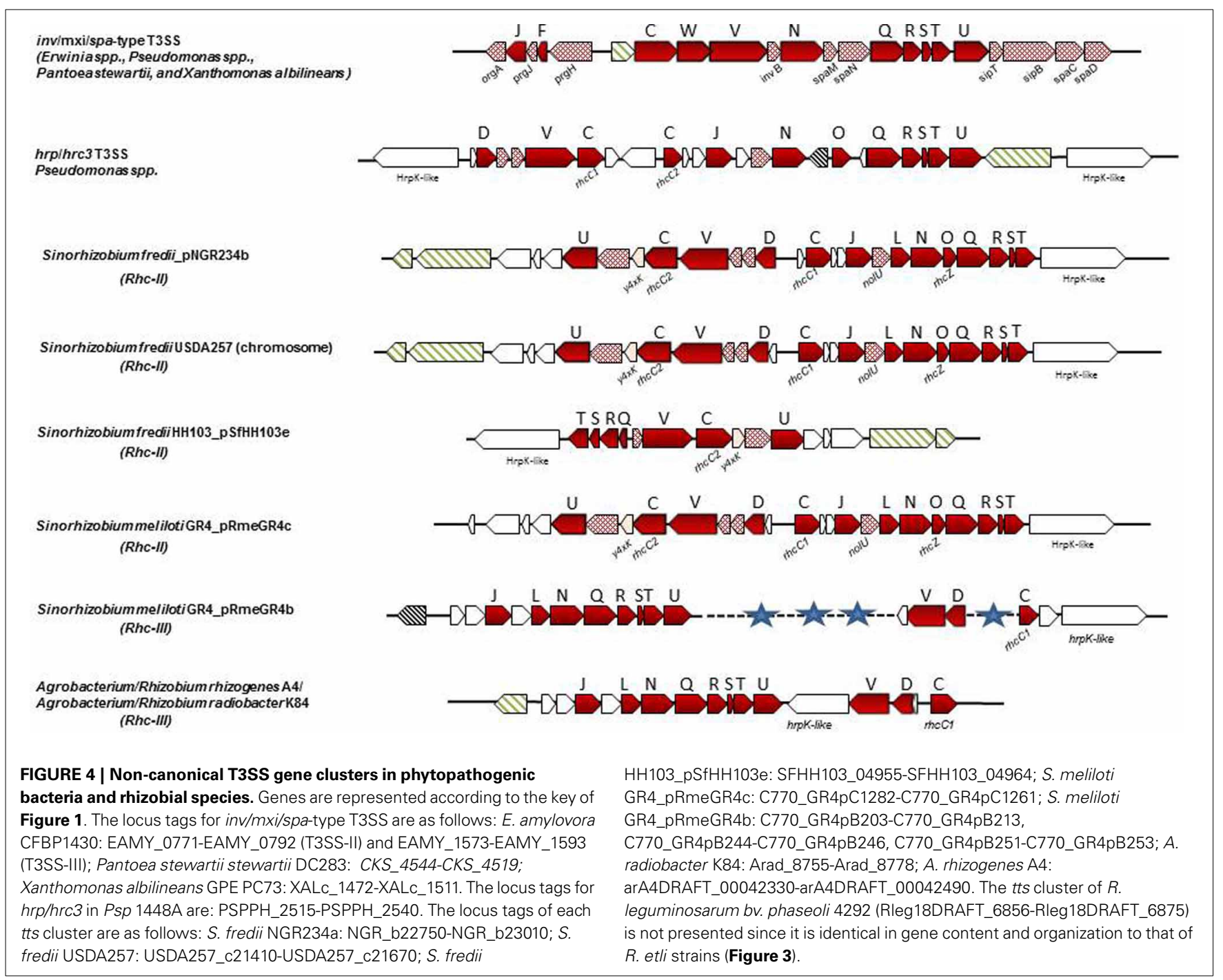

plasmid pSfrHH103e (T3SS-II), which harbors genes for the production of diverse surface polysaccharides (Margaret et al., 2011). The T3SS-II is similar with a part of the second T3SS of NGR234 (Figure 4). S. fredii USDA 257 also carries a second T3SS which is located on the chromosome and is almost identical to the T3SS-II of NGR234 in respect to gene content and genetic organization but its role is also unidentified (Schuldes et al., 2012).

\section{Rhc-III GENE CLUSTERS}

The Rhc-III group contains the T3SSs found in the two sequenced R. etli strains (Table 2). The T3SS cluster is located on the symbiotic plasmid $\mathrm{p} 42 \mathrm{~d}$ of $R$. etli CFN42 and on plasmid $\mathrm{pB}$ of R. etli CIAT 652 (González et al., 2006; Gazi et al., 2012). The organization of the rhc genes is also different from that in other rhizobia (Figure 3). In addition, some of the core components of the T3SS that are present in other rhizobia and phytopathogenic bacteria were not detected on Rhc-III tts clusters. For example, the rhcC2 is absent in both R. etli strains (González et al., 2006; Gazi et al., 2012). In addition, the lack of discernible tts boxes in the upstream regions of $r h c$ genes and the absence of homology between the TtsI and the putative transcriptional regulator (RHE_PD00067) located at the 3'- end of the cluster suggests that the T3SS of R. etli strains might not be regulated similarly to the T3SS of other rhizobia. Interestingly, a gene associated with the $r h c$ genes is $h r p W$ and it is highly conserved among diverse R. etli strains (Fauvart et al., 2009). Remarkably, the draft rhizobial genomes of $R$. leguminosarum bv. phaseoli 4292, FA23, and R. leguminosarum CCGE 510 harbor genes coding for core T3SS components, while no components of the T3SS have been found in the published genome sequences of $R$. leguminosarum biovars (bv. viciae 3841, bv. trifolii WSM2304 and bv. trifolii WSM1325). The putative T3SS genes of R. leguminosarum strains are located in two putative operons close to each other and are highly similar in content and gene organization with those found in R. etli strains. Moreover, next to the T3SS gene cluster, there are two genes coding for proteins similar to members of StcC and SctO families and a gene coding for a putative transcriptional regulator assigned to COG1396. The R. leguminosarum T3SS gene clusters are grouped phylogenetically with those of rhizobia belonging to Rhc-III group (Figure 2, Table 2). 
T3SS gene clusters belonging to Rhc-III group are also evident in the draft genome sequences of two Agrobacterium strains. Although, the current taxonomic status of Agrobacterium spp. and Rhizobium spp. remains confusing, a proposal was made in 2011 by the 'Subcommittee on the taxonomy of Agrobacterium and Rhizobium' to reclassify the biovars 2 of Agrobacterium into the genus Rhizobium (Lindström and Young, 2011). Agrobacterium radiobacter K84, a biocontrol agent, and Agrobacterium rhizogenes A4 have been proposed to be designated as Rhizobium rhizogenes K84 and A4, respectively. Since these bacteria are not legume-nodulating bacteria, their reclassification into the genus Rhizobium is not fully supported within the scientific community. In the present article the term "rhizobia" is used in the strictest sense and includes members of the genus Rhizobium. Interestingly, the complete genome of K84 (available from GenBank and from the Agrobacterium genome database http:// agro.vbi.vt.edu/public) and the draft genome of A4 (available from DOE Joint Genome Institute) harbor a putative T3SS gene cluster (Setubal et al., 2009; Slater et al., 2009; Figure 4, Table 2). Instead, the complete genomes of the pathogenic strains Agrobacterium tumefaciens C58 (biovar 1), and Agrobacterium vitis S4 (biovar 3) lack a T3SS. Notably, the T3SSs of K84 and A4 are most similar in gene content, organization and phylogenetic position to those belonging in Rhc-III group, while some slight differences are evident (Figures 2, 4). For example, a $h r p W$ homolog is missing and a gene coding for an unknown protein of 1060 aa resides in the corresponding region. Remarkably, this putative protein displays low similarity to HrpK1 proteins from $P$. syringae. In addition, a gene coding for member of SctO family is also lacking.

\section{$\beta$-Rhc GENE CLUSTERS}

The $\beta$-Rhc subgroup is represented by $C$. taiwanensis, a $\beta$ rhizobium capable of nodulating Mimosa species and fixing $\mathrm{N}_{2}$ within the nodules (Gyaneshwar et al., 2011; Table 2). Unlike $\alpha$-rhizobia and $\beta$-proteobacteria (e.g., R. solanacearum), C. taiwanensis contains a distinct T3SS with a different genetic organization, but similar to that of the human opportunist Burkholderia cenocepacia, suggesting a common origin for these two secretion systems (Amadou et al., 2008). In addition, none of the effector genes identified in $\alpha$-rhizobia or $R$. solanacearum have been detected in $C$. taiwanensis. The T3SS genes reside on chromosome 2 and are organized possibly in four operons (Figure 3). A recent study showed that, in contrast to $\alpha$-rhizobia, glutamate rather than flavonoids induced T3SS expression in C. taiwanensis grown in minimal media (Saad et al., 2012). Interestingly, a similar T3SS induction has been reported for Pseudomonas aeruginosa and R. solanacearum (Cunnac et al., 2004). Since these experiments were performed in vitro, caution should be taken before making assumptions for their regulatory networks controlling these T3SSs as the in vivo signals that activate them remain unknown in both rhizobia and pathogenic bacteria. Despite that $C$. taiwanensis has a functional T3SS, its inactivation did not affect nodulation of its primary host Mimosa pudica, but it acquired the ability of establishing chronic infections and fixing nitrogen in Leucaena leucocephala, a species belonging to the same Mimoseae tribe as M. pudica (Saad et al., 2012).

\section{COMPARISON OF T3SS CORE PROTEINS IN PHYTOPATHOGENIC BACTERIA AND RHIZOBIA}

A marked difference among the T3SS clusters of phytopathogenic and rhizobial bacteria is that the gene coding for the outer membrane secretin SctC is split in two ORFs, called rhcC1 (formerly nolW) and $r h c C 2$, which encode the $\mathrm{N}$ - and C-terminal domains of $\mathrm{HrcC}$, respectively. Both parts of the split gene are separately located in the tts clusters. An analogous situation occurs in B. elkanii strains in which the secretin gene is more split into three ORFs, rhcC1, $r h c C 2$, and $r h c C 3$ (Okazaki et al., 2009; de Souza et al., 2012). The split secretin gene is a distinguishing feature of rhizobial T3SS clusters known so far, except for $R$. etli strains in which the $r h c C 2$ is absent. Similary, the $h r c C$ gene of T3SS clusters of the $P$. syringae pathovars belonging to Rhc-II family subgroup is split into two ORFs, except for P. syringae pv. tabaci ATCC 11528 in which the $h r c C$ gene is split into three ORFs (Gazi et al., 2012). Interestingly, no $t t s$ box is present in the promoter region of rhcC1 of S. fredii NGR234, USDA 257, HH103 and Bja USDA 110 although the protein is considered to be part of the transport complex of the T3SS, located in the outer membrane (Viprey et al., 1998). Previous studies have shown that $r h c C 1$ may be constitutively expressed in S. fredii NGR234 (Marie et al., 2004), Bja USDA 110 (Krause et al., 2002) and in S. fredii USDA257 (Kovács et al., 1995). These features suggest that alternative regulatory signals control the rhcC1 expression and the protein might have an additional, still unknown, function. In a similar vain, the rhizobial SctQ proteins are single polypeptides (Viprey et al., 1998) as those in $h r p / h r c 2$ T3SSs, while in $h r p / h r c 1$ T3SSs, two split genes ( $h r c Q a$ and $h r c Q b$ ) encode the N-and C-terminal parts which are fused into one protein (HrcQ). Lastly, proteins belonging to less conserved T3S families, but exerting regulatory roles such as the SctP, which controls the needle-length during its assembly (Journet et al., 2003), have not yet been identified in any rhizobial species suggesting that either rhizobial-specific proteins with no sequence homology but analogous roles might exist or such a regulatory mechanism might not be required for rhizobial T3SS. In addition, members of SctO family have not been identified in rhizobia of Rhc-I subgroup, but are present in rhizobia of RhcII subgroup. It is likely that proteins belonging to less conserved families might have considerably diverged to fulfil the structural and functional requirements of each T3SS.

\section{HRP PILI AND RHIZOBIAL SURFACE APPENDAGES}

T3SSs from different bacteria assemble surface appendages that are considered to serve as a channel for protein delivery into host cells (translocation). The T3SS appendages of animal pathogenic bacteria are well-characterized and morphologically resemble a needle, while phytopathogenic bacteria assemble a thinner and longer filamentous appendage, called the Hrp pilus. For a detailed comparison of these systems, the reader is referred to a recent excellent overview article (Büttner, 2012). Hrp pili have been visualized by electron microscopic studies in $P$. syringae, $R$. solanacearum, E. amylovora, and Xanthomonas campestris (Roine et al., 1997; Van Gijsegem et al., 2000; Jin et al., 2001; Weber et al., 2005). The major protein subunits (pilins) are HrpA in $P$. syringae and E. amylovora, $\mathrm{HrpY}$ in R. solanacearum, and HrpE in $X$. campestris. Pilins form a narrow channel with comparable 
dimensions in diameter [P. syringae $(6-8 \mathrm{~nm}), R$. solanacearum $(6.6 \mathrm{~nm})$, E. amylovora $(8 \mathrm{~nm})$ and $X$. campestris $(8-10 \mathrm{~nm})]$ and can reach more than $2 \mu \mathrm{m}$ in length (Roine et al., 1997; Van Gijsegem et al., 2000; Jin et al., 2001; Weber et al., 2005). All are small proteins (6 to $11 \mathrm{kDa}$ ) and share low or no similarity among species/pathovars of different phytopathogenic bacteria. Despite their sequence variability share similar physicochemical and structural properties, increased flexibility, and polymerization modes. Genetic and phylogenetic studies have provided evidence that plant pathogenic bacteria evolved functionally and structurally similar pilins to avoid plant recognition (Lee et al., 2005; Weber et al., 2005; Guttman et al., 2006; Weber and Koebnik, 2006).

By analogy to plant pathogens, rhizobia assemble pilus-like surface appendages. So far, these pili have been visualized in three rhizobial species, S. fredii NGR234, USDA257, and USDA191 (Krishnan et al., 2003, 2011; Marie et al., 2003; Deakin et al., 2005; Saad et al., 2005). Similar to Hrp pili, the rhizobial piluslike appendages are thin filaments with a diameter $6-8 \mathrm{~nm}$ and are formed in a flavonoid- and T3SS-dependent manner. Biochemical and electron microscopic studies have shown that three proteins were mainly associated with isolated surface appendages produced by NGR234, USDA257, and USDA191: NopA, NopB, and NopX (Krishnan et al., 2003, 2011; Marie et al., 2003; Deakin et al., 2005; Saad et al., 2005). The major subunit of rhizobial pili is the NopA protein, which is found only in T3SS-possessing rhizobial species and show no homology to pilins from plant pathogens. Common features of the pilins from phytopathogenic and rhizobial bacteria are their small size ranging between 66113 aa and 63-71 aa, respectively, and their secondary structure is predicted to consist almost exclusively from $\alpha$-helices, except for their N-termini (He et al., 2004; Deakin et al., 2005; Weber and Koebnik, 2005). In contrast to phytopathogenic bacteria the pilin proteins from different rhizobial strains are more similar to each other. The NopA protein from $S$. fredii NGR234 shares 99, 65, and $42 \%$ identity to the NopA proteins from $S$. fredii USDA257, $M$. loti, and Bja USDA110, respectively (Marie et al., 2003). Given the small size of rhizobial pilins, their presence in all functional T3SScontaining rhizobia, and its role in pilus formation, it would be possible that NopA might be able to polymerize and form a channel as in plant pathogens. However, future studies are needed to determine whether rhizobial pilins have similar properties with their counterparts in phytopathogenic bacteria.

NopB proteins are also present only in T3SS-containing rhizobial strains, have similar size and share high similarity especially at their C-termini. NopB from NGR234 shares 98, 63, and 43\% homology to NopB from USDA257, M. loti and Bja USDA110, respectively. Moreover, NopB proteins share similarity at their conserved C-termini with FlgK proteins, known minor components of flagella in many Gram-negative bacteria (Saad et al., 2005). Genetic and electron microscopic studies have shown that NopB proteins from NGR234 and USDA257 are integral parts of rhizobial pili based on the following findings: non-polar $\triangle$ nopB mutants of both strains are unable to secrete any Nops in culture, do not form pili and their nodulation phenotypes resemble those exhibited by $\Delta n o p A$ and $\Delta r h c N$ mutants (Viprey et al., 1998; Lorio et al., 2004; Saad et al., 2005; Kim and Krishnan, 2014).
Furthermore, direct interaction of NopA and NopB was demonstrated by coimmunoprecipitation assays, while direct interaction with NopX could not be confirmed, due to its toxicity after overexpression in E. coli. However, it was coimmunoprecipitated with NopA and NopB from isolated surface appendages (Saad et al., 2008). A possible model have been proposed for the architecture of rhizobial pilus predicting that it is mainly composed by NopA and NopB, with the latter functioning possibly as a coupling protein within the pilus, while NopX might be part of the distal end of the pilus (Saad et al., 2008).

An interesting morphological difference between Hrp pili and those produced by NGR234 was that the latter formed a highly branched network of fibrils of variable width causing the cells to aggregate (Deakin et al., 2005). This was attributed to the presence of exopolysaccharides (EPS), known to be produced in large amounts by NGR234. Indeed, a mutant (exoY) unable to synthesize EPS could not produce surface appendages, albeit NopA was secreted. This finding raises questions whether EPS have a stabilizing role in rhizobial pili or reflect adaptations for rhizobia to avoid detection by the plant immune system. Recently, distinct morphological differences in T3SS-dependent pili produced by two other rhizobial species, S. fredii USDA257 and USDA191, were also visualized (Krishnan et al., 2011). USDA191 pili were short, rod shaped with a diameter $10-13 \mathrm{~nm}$, while USDA257 produced long thin filaments with a diameter $6-8 \mathrm{~nm}$ similar to that of NGR234. Whether these two types of pili exhibit differential abilities to deliver effector proteins into the soybean root cells awaits investigation.

\section{TRANSLOCATORS}

Translocators are T3SS proteins which are considered to form a putative pore (translocon) into the eukaryotic membrane for effector protein translocation. Although the protein composition and structure of the translocon is well characterized in animal pathogenic bacteria, it is less studied in phytopathogens. Translocon proteins from animal-pathogenic bacteria are not conserved among different species, but they generally share some common functional and structural features: (i) they are secreted proteins, (ii) they are not required for effector secretion in culture through the T3SS, but contribute to effector translocation into eukaryotic cells, (iii) knockout mutants could be functionally complemented, though partially, by translocators from the same or other phylogenetically distant species, (iv) they harbor transmembrane domains, and (v) they possess the ability to form pores in artificial lipid bilayers. Several lines of evidence suggest that a similar structure may exist in phytopathogens since they possess T3SS proteins with similar features to those mentioned above. So far, as candidate translocon components are considered to be the HrpF from X. campestris, PopF1 and PopF2 from $R$. solanacearum and HrpK1 from P. syringae and E. amylovora (Büttner et al., 2002; Petnicki-Ocwieja et al., 2005; Meyer et al., 2006; Büttner and He, 2009). Interestingly, the contribution of these proteins to pathogenicity differs being either essential (HrpF) or dispensable (HrpK1, PopF1 and PopF2) for effector translocation. Experimental evidence reasoned this difference on the possible additive effects of harpins or harpin-like proteins of $P$. syringae and E. amylovora in effector translocation 
(Petnicki-Ocwieja et al., 2005; Meyer et al., 2006; Kvitko et al., 2007; Bocsanczy et al., 2008). Based on genetic analyses and on putative or proven functional properties of harpins from $P$. syringae, it has been suggested that they may act together to form translocation complexes (Petnicki-Ocwieja et al., 2005; Kvitko et al., 2007). For example, several harpins are two domain proteins (HrpW of E. amylovora, HrpW1 and HopAK1, and PopW of $R$. solanacearum) and contain pectate lyase-like domains that suggest potential interactions with plant cell wall components (Charkowski et al., 1998; Kim and Beer, 1998; Li et al., 2010). Other harpins have been found to associate with artificial lipid bilayers and to form pores (Lee et al., 2001; Racape et al., 2005; Engelhardt et al., 2009). A similar property is also exhibited by the translocator protein $\mathrm{HrpF}$ of $X$. campestris pv. vesicatoria (Büttner et al., 2002). It is remarkable that the ability of forming pores, albeit in synthetic membranes, occurs either in putative translocators or harpins in $X$. campestris and P. syringae, respectively. Considering that $\mathrm{HrpF}$ is essential for effector translocation while HrpZ is not, it may suggest that the translocon function might be determined by the allocation of functionalities in different proteins depending on the species.

In contrast to phytopathogenic HrpW homologs (E. amylovora HrpW, P. syringae HrpW1 and HopAK1, and R. solanacearum PopW), the R. etli HrpW exhibits pectate lyase activity (Fauvart et al., 2009; Choi et al., 2013). Comparative sequence analysis showed that the $R$. etli HrpW groups together with homologs of phytopathogenic bacteria suggesting a common ancestry, albeit they differ in critical amino acids essential for the pectinolytic activity of the $R$. etli HrpW. These aminoacids are conserved between characterized pectate lyases and $R$. etli HrpW but not in phytopathogenic homologs, with the exception of Acidovorax avenae, which could account for the lack of pectinolytic activity of HrpW homologs from phytopathogenic bacteria (Fauvart et al., 2009). Remarkably, phytopathogenic HrpW homologs are secreted through the T3SS (Charkowski et al., 1998; Kim and Beer, 1998; Li et al., 2010), while the $R$. etli HrpW was not detected in extracellular milieu following growth of $R$. etli in minimal media (Fauvart et al., 2009). However, it is not known whether the $R$. etli T3SS genes are induced in such media which could account for this discrepancy.

The HrpW homologs in both symbiotic and pathogenic bacteria share similarities in respect to their contribution on the symbiotic and virulent phenotypes, respectively. Despite the fact that $h r p W$ is induced during the early stages of root infection and inside nitrogen-fixing nodules, this induction is flavonoidindependent and it is not essential for symbiosis of $R$. etli with the common bean Phaseolus vulgaris (Fauvart et al., 2009). It is worth noting that $R$. etli posseses two HrpK-like proteins in the T3SS cluster which share low homology with HrpK proteins from P. syringae pathovars and Erwinia species. Thus, it is likely that the role of HrpW in symbiosis, if any, could be masked by the function of this protein. By analogy, the P. syringae HrpW homologs (HrpZ1, HrpW1, and HopAK1) exhibit functional redundancy and possess a minor role in virulence (Charkowski et al., 1998; Gaudriault et al., 1998; Kim and Beer, 1998; Kvitko et al., 2007; Li et al., 2010).
So far, neither $h r p W$ nor $h r p K$ homologs have been reported in other T3SS-containing rhizobia, although HrpK-like proteins may be encoded by the atypical T3SS gene clusters of some rhizobial species (Figure 4, author's unpublished data). However, NopX (formerly NolX) displays similarity to HrpF, but the possible role of NopX as a translocator has not yet been studied (Huguet and Bonas, 1997). Interestingly, $\Delta$ nopX mutants of NGR234 were able to secrete Nops in culture (Marie et al., 2003; Deakin et al., 2005). This secretion-deficient phenotype is reminiscent of that displayed by mutants in translocators from phytopathogenic bacteria. For example, secretion of $P$. syringae effectors in culture was not affected in a polymutant deleted in harpin genes and hrpK1 (Kvitko et al., 2007). Similarly, popF1 and popF2 mutants of $R$. solanacearum did not impair effector secretion (Meyer et al., 2006). Although Bja USDA110 genome does not contain nopX, it possesses a gene (blr1993) coding for a putative polygalacturonase which is inducible by the plant isoflavonoid genistein (Caldelari Baumberger et al., 2003) and its product is secreted (Hempel et al., 2009). Recently, blr1993 was classified as a candidate T3E gene called nopAC, based in the presence of a tts box in its upstream region and the positive phenotype in the translocation assay (Kimbrel et al., 2013). No T3E proteins have been identified so far with a putative polygalacturonase domain in T3SS-containing rhizobia. Nevertheless, the presence of cell wall-degrading enzymes in $R$. etli and B. japonicum suggests that they might contribute to the symbiotic process, although the link between T3SS and HrpW in R. etli remains to be addressed. Taken together, these similarities possibly suggest that both pathogenic and symbiotic bacteria use similar strategies in initial stages of infection, while the differences may reflect adaptations to different plant hosts.

\section{ATYPICAL TYPE III SECRETION SYSTEMS}

Many Gram-negative bacteria contain either non-canonical T3SSs with differences in gene composition, structure, regulation and function or more than one T3SSs. For example, Salmonella spp. possess two T3SSs which are used in different stages of infection (Hansen-Wester and Hensel, 2001). Intriguingly, Burkholderia spp. such as B. pseudomallei, harbor three T3SSs: one SPI-1-like T3SS and two Hrp-like T3SSs with the first one functioning in animal hosts and the second ones in plant hosts (Rainbow et al., 2002; Stevens et al., 2002, Figure 1). Similarly, several strains of plant pathogenic bacteria and rhizobial species carry more than one T3SSs. Most additional T3SSs are differentiated from the typical T3SSs by the lack of some structural components and/or regulatory elements, while their role in interactions with plants is yet unknown.

\section{RHIZOBIA}

To date, multiple T3SSs have only been found in Sinorhizobium species. As described above $S$. fredii NGR234, USDA257 and HH103 possess two T3SSs, one belonging to Rhc-I subgroup (Figures 2, 3, Table 2) and a second one belonging to Rhc-II subgroup (Figures 2, 4, Table 2). Recently, comparative genomics of 48 Sinorhizobium strains revealed the presence of T3SS gene clusters in some strains of S. meliloti, S. saheli, S. fredii, and S. terangae (Sugawara et al., 2013). All tts clusters contain the 
main operon rhcJ-nolUV-rhcNQRST but the overall gene organization is different and the identified T3SS clusters are classified into three types: a, b, and c, which belong to Rhc-II, Rhc-I, and Rhc-III subgroups, respectively (Figure 2). Notably, the T3SSs are not widely distributed in S. meliloti strains since 9 out of 33 sequenced strains possess a T3SS (Sugawara et al., 2013, Table 2). Interestingly, none of S. meliloti T3SS-containing strains harbor the typical tts gene cluster (Rhc-I) found so far in strains of Sinorhizobium species, but contain a Rhc-II T3SS, which is similar to that located on plasmid pNGR234b (Table 2). From the nine S. meliloti strains studied by Sugawara et al. (2013), only the strain S. meliloti M195 carries two T3SSs belonging to Rhc-II and Rhc-III (Table 2). Furthermore, the genome of Sinorhizobium meliloti GR4 also contains two T3SS gene clusters, one located in the symbiotic megaplasmid pRmeGR4c and the second one in the accessory plasmid pRmeGR4b (Martínez-Abarca et al., 2013). The former belongs to the Rhc-II subgroup and the latter to the Rhc-III (Figure 2). Remarkably, the main operon ( rhcJ-nolUVrhcNQRST) of the T3SS located in the megaplasmid is separated from the genes coding for members of SctV, D, and C families with a long region $(\sim 30 \mathrm{~kb})$ rich in mobile elements and it could be considered as atypical one in a sense (Figure 4).

S. terangae USDA 4894 also harbors two T3SSs belonging to Rhc-I and Rhc-III (Sugawara et al., 2013, Figure 2, Table 2). The latter resembles that of $R$. etli strains, except that a putative gene, instead of $h r p W$, is lying between $r h c U$ and $r h c V$ that encodes a hypothetical protein. A common feature of Rhc-II and Rhc-III T3SSs found in S.meliloti, S. saheli, and S. terangae c is the lack of known nop genes coding for components of T3SS-dependent surface appendages (NopA, NopB, and NopC) or effector proteins. Moreover, no $t t s I$ genes were detected in any of these $t$ ts clusters.

Despite that the T3SS of B. elkanii USDA 61 contains all the core T3SS genes and the regulatory elements that are present in the typical tts gene clusters of Rhc-I subgroup, it exhibits a novel combination of genes with a hybrid genetic organization displaying similarities with the tts clusters of B. japonicum and NGR234 (Okazaki et al., 2009; Figure 3, Table 2). Similarly, the draft sequence of the genome of B. elkanii 587 revealed the presence of a $t$ ts gene cluster similar to that found in $B$. elkanii USDA 61 (de Souza et al., 2012). Both B. elkanii T3SSs possess nopX, which is absent in the close relative $B$. japonicum, but it is present in S. fredii strains (Figure 3). On the other hand, the ORFs upstream of $\mathrm{rhcV}$ are similar to those from B. japonicum but are absent from $S$. fredii and $M$. loti strains. Another unique feature of the B. elkanii T3SS is the split of the secretin gene in three ORFs: $r h c C 1$, $r h c 2$, and $r h c C 3$. The latter shares similarity with the central part of $r h c C 1$. In addition, the $t t s$ cluster of B. elkanii USDA 61 harbors genes that they have not been found in other $t$ ts clusters or to database entries or show similarity to non-rhizobial genes. The T3SS of B. elkanii USDA 61 is functional since its inactivation resulted in different symbiotic phenotypes depending on the host (Okazaki et al., 2009). However, genistein, a known inducer of the $B$. japonicum tts cluster, did not affect the secretion of Nops suggesting that the regulation of B. elkanii T3SS may be different from that in other rhizobia (Okazaki et al., 2009). Indeed, a recent intriguing study revealed that $B$. elkanii T3SS is capable of activating host nodulation signaling in the absence of Nod factors (NFs) and leguminous receptors (NFRs), which are considered to be key factors for symbiosis initiation (Okazaki et al., 2013). Besides, the absence of root-hairs and infection threads on the soybean roots inoculated with USDA61 suggested that B. elkanii T3SS may promote intercellular infection by analogy to Salmonella infection process. These findings show that B. elkanii T3SS is peculiar not only in genetic organization but also in function. It is worth mentioning that T3SSs from other rhizobial species are considered to be involved in the release of rhizobia from infection threads (Krishnan, 2002; Deakin and Broughton, 2009; Okazaki et al., 2010). Altogether these observations unveil that rhizobial T3SSs may contribute differentially in the nodulation process depending either on the rhizobial species or on the particular combination of symbiotic partners.

\section{Pseudomonas spp.}

Pseudomonas syringae pv. phaseolicola 1448A (Pph 1448A) carries a second T3SS gene cluster, which is phylogenetically clustered together with those found in rhizobia, while individual homologs are found in Photorhabdus, Aeromonas spp. and in P. aeruginosa (Joardar et al., 2005; Gazi et al., 2012) This T3SS is suggested to be called $h r p / h r c 3$, since it defines a distinct lineage in the Rhc family (Figure 1). Although it contains genes coding for all essential T3SS core components, its function is yet unknown and it is possibly unable to translocate effectors into plant cells (O'Brien et al., 2011). It neither harbors hrp promoter boxes in the upstream regions of T3SS genes nor genes coding for HrpLlike transcriptional regulators, albeit a gene coding for a putative transcriptional regulator is located at the $3^{\prime}$ end of the cluster (Figure 4). The absence of typical T3SS regulatory elements suggests that it may be controlled by alternative regulatory cirquits. The presence of this distinct T3SS has also been revealed in the draft genomes of several $P$. syringae pathovars with almost identical gene content and genetic organization to those found in $P p h$ 1448A (Figure 1, Table 1), while it is absent in other pathovars, such as P. s. pv. tomato DC3000, and P. s. pv. syringae B728A (Reinhardt et al., 2009; Studholme et al., 2009; Green et al., 2010; Rodríguez-Palenzuela et al., 2010; Baltrus et al., 2011; Qi et al., 2011; O'Brien et al., 2012; Lefort et al., 2013). Future work is needed to shed light on the role, if any, and the evolutionary history of these T3SSs.

Another atypical T3SS was unveiled by genome sequencing of P. pv. syringae 642 (Psy642), a non-pathogenic strain isolated from a healthy leaf from an unidentified herbaceous plant (Mohr et al., 2008; Clarke et al., 2010). Although Psy642 is closely related to $P$. syringae $\mathrm{B} 728 \mathrm{a}($ PsyB728a), it possesses a highly divergent $\mathrm{hrp} / \mathrm{hrc}$ cluster which is located in a different genomic region than that occupied by the typical $h r p / h r c$ cluster of PsyB728a (Clarke et al., 2010). The core components ( $\mathrm{Hrc}$ ) of this T3SS are more similar to those of PsyB728a than those present in other $P$. syringae strains. The distinct phylogenetic position of Psy642 in relation to other P. syringae strains in the $\mathrm{HrcU}$ tree suggests that the Psy642 $\mathrm{hrp} / \mathrm{hrc}$ cluster may have different evolutionary history and possibly it is more primitive than the canonical P. syringae hrp/hrcl clusters (Clarke et al., 2010; Figure 1).

A main structural difference of this atypical cluster is the lack of $h r p S$ coding for a response regulator which together with HrpR 
activate expression of HrpL, the master transcription factor of the typical $h r p / h r c$ clusters present in other P. syringae strains (Xiao and Hutcheson, 1994; Xiao et al., 1994). However, genes with similarity to $h r p R$ and $h r p L$ of $P s y B 728 a$ are present in the same position as in the archetypal $P$. syringae $h r p / h r c$ clusters. hrp boxes highly similar to that found in other $h r p / h r c$ clusters (Xiao et al., 1994) are present upstream of some predicted operons but less conserved motifs were also identified in other operons of the cluster suggesting that Psy642 HrpL might exhibit a slightly different DNA binding specificity (Clarke et al., 2010). Another remarkable difference of this new cluster is the lack of $h r p A$ coding for the major subunit of Hrp pili, while an open reading frame (ORF) of unknown function has occupied the conserved genome position of $h r p A$. The Psy642 hrp/hrc cluster also lacks T3SS translocators found in other $P$. syringae strains, except for $h r p Z$, raising questions about the efficiency of effector translocation. Additionally, the Psy642 hrp/hrc cluster contains a very limited effector repertoire carrying only homologs of avrE, hopM1, and hopB, though very distantly related to their homologs in other $P$. syringae strains (Clarke et al., 2010; O'Brien et al., 2011). Flanking the cluster, there are two ORFs possibly organized in an operon that is preceded by a hrp box and code for putative effectors since they possess the physicochemical features of known T3Es. At the left border of the cluster, two ORFs are present: one carries a $h r p$ box and codes for a protein similar to the effector ExoY of the opportunistic animal pathogen $P$. aeruginosa and another one, without a $h r p$ box, codes for a putative lytic transglycosylase (candidate translocator), but lacking features typical of T3Es. Lastly, an ORF located in a different genomic location resembles the T3E ExoU of $P$. aeruginosa, although it does not harbor the features typical of T3Es and no hrp box is present. In contrast to other atypical T3SSs, the Psy642 T3SS appear to be constitutively expressed and functional but it does not play a major role during in planta growth. Psy642 was able to ectopically express the HrpLdependent promoter of avrPto in rich and minimal media and to translocate AvrRpt2 into A. thaliana cells (Clarke et al., 2010).

Atypicall $h r p / h r c$-like clusters similar to that of Psy642 appear to be common among $P$. syringae strains isolated from healthy plants and they belong to a distinct phylogenetic subgroup within group 2 of the P. syringae complex (Hwang et al., 2005; Mohr et al., 2008). All these strains do not induce an HR and do not cause disease on any tested plant species (Mohr et al., 2008). Despite their apparent lack of pathogenic lifestyle, the presence of genes encoding virulence factors, such as T3SS and phytotoxins, could not exclude the possibility of being pathogenic either on plant or non-plant hosts.

An unusual case, but different from those described above, is the polymorphic T3SS of Pseudomonas viridiflava (Araki et al., 2006). Two structurally distinct and highly divergent paralogous T3SSs are found in different chromosomal locations, but only one is present in each isolate. One has the typical tripartite organization present in the $P$. syringae hrp/hrc clusters, named T-PAI (tripartite pathogenicity island). The second one, named S-PAI (single pathogenicity island), is a single $h r p / h r c$ locus similar in nucleotide sequence and gene structure to the $P$. cichorii (Hojo et al., 2008). P. viridiflava strains carrying any of the two paralogous T3SSs exhibit distinct differences in virulence and host specificity. Araki et al. (2006) have suggested that the maintenance of the dual PAI system may be attributed to the interaction with different hosts. The S-PAI and P. cichorii T3SSs lack the flanking EEL and CEL loci found in the canonical $h r p / h r c 1$ clusters, while the genes coding for AvrE1 and its chaperone AvrF1 are lying between $h r c U$ and $h r c V$. Besides, both T3SSs are phylogenetically related to each other and distinct from the canonical $h r p / h r c l$ clusters indicating a possible different evolutionary history, whereas they are closely related with those found in soft rot bacteria such as Erwinia spp. (Figure 1). Interestingly, the $P$. cichorii T3SS affects virulence in a host-dependent manner as being essential for the interaction with eggplant but not with lettuce. Hojo et al. (2008) suggested that $P$. cichorii likely exhibits either biotrophic or necrotrophic lifestyle depending on the host, which may account for the differential contribution of T3SS in different hosts.

Lastly, T3SSs are widespread within the Pseudomonas fluorescens/putida complex (Preston et al., 2001; Mazurier et al., 2004; Warmink and van Elsas, 2008; Kimbrel et al., 2010; Viollet et al., 2011). Despite their similarity in gene content and organization to T3SS gene clusters of phytopathogenic bacteria belonging in the Hrp/Hrcl family (Figure 1, Table 1), they possess several unique features such as lack of some individual T3SS components, different regulatory mechanisms and novel roles. In a sense, these T3SSs could be considered as atypical ones in terms of regulation and function. Several studies have provided evidence for their implication in processes related with biocontrol activity, resistance to bacteriovore predation, bacterial-fungal interactions, mycorrhization and soil colonization (Preston et al., 2001; Rezzonico et al., 2004, 2005; Jackson et al., 2005; Warmink and van Elsas, 2008; Cusano et al., 2011; Mavrodi et al., 2011; Viollet et al., 2011; Maketon et al., 2012; Redondo-Nieto et al., 2013). Besides the presence of divergent $h r p / h r c l$ gene clusters in fluorescent Pseudomonads, several strains also possess T3SSs belonging to the Rhc and Inv/Mxi/Spa families (Table 1 and references therein). For more details on these T3SSs, the reader can refer to more relevant literature, since their description is not within the scope of the present article.

\section{Erwinia spp.}

Multiple and non-canonical T3SSs are also present in the genomes of Erwinia species. Three T3SSs have been found in the complete genomes of two E. amylovora strains, CFBP 1430 and ATCC49946 (Oh and Beer, 2005; Bocsanczy et al., 2008; Sebaihia et al., 2010; Smits et al., 2010b). One (T3SS-I) is similar in content and gene organization with the canonical $h r p / h r c$ clusters of E. amylovora strains Ea321 and Ea273 (ATCC49946), known for their role in pathogenicity (Oh and Beer, 2005; Bocsanczy et al., 2008). These $h r p / h r c$ gene clusters are also flanked by the regions HEE ( Hrp effectors and elicitors), HAE ( Hrp-associated enzymes), and IT (Island transfer) (Oh and Beer, 2005). The other two T3SSs (T3SS-II and T3SS-III; Figure 1) are related to the inv/mxi/spa gene clusters of animal pathogens (e.g., Salmonella and Shigella spp.) and also resemble to the additional T3SSs found in the phytopathogens, E. pyrifoliae DSM 12163 (Smits et al., 2010a), E. amylovora 273 (Bocsanczy et al., 2008), E. amylovora 321, in the epiphytic strain E. tasmaniensis Et1/99 
(Kube et al., 2010), in the insect endosymbiont Sodalis glossidinius (Dale et al., 2001) and in bacteria of the P. fluorescens group, such as $P$. fluorescens Q2-87 (Loper et al., 2012), P. fluorescens F113 (Redondo-Nieto et al., 2013), P. fluorescens HK44 (Chauhan et al., 2011), while differences in individual T3SS components have been reported (Barret et al., 2013). Furthermore, incomplete T3SSs of the Inv/Mxi/SpaS type have been found in several strains of Pseudomonas spp. which interact with non-plant hosts such as mushrooms, nematodes or are soil colonizers with yet unknown biotic relationships (Barret et al., 2013, Table 1). Although the role of these T3SSs is still unknown, their presence in non-pathogens may be indicative of their contributions to biotic associations with non-plant hosts or to the environmental fitness of bacteria. Indeed, deletion of both T3SSs (II and III) from the E. amylovora genome demonstrated that they are not essential for virulence in plants (Zhao et al., 2009). On the other hand, the similarity of these T3SSs to that of the insect endosymbiont Sodalis glossidinius str. morsitans has led to the assumption that they may facilitate to as yet unknown interactions with insects. Notably, the second T3SS cluster of Pantoea stewartii subsp. stewartii belonging to the Inv/Mxi/Spa type T3SSs is required for bacterial persistence in its insect vector and subsequent transmission by the vector to host plants, while its Hrp/Hrcltype T3SS is involved in plant colonization (Correa et al., 2012; Figures 1, 4). Recent studies provide evidence that the Inv/Mxi/Spa type T3SSs found in some plant beneficial bacteria may be involved in interactions with nonplant hosts. For example, the second T3SS cluster of $P$. fluorescens F113 is induced during F113-amoeba interactions and seems to be involved in resistance to bacteriovorous protists, while the role of its Hrp/Hrcl-type T3SS is yet unknown (Barret et al., 2013). Lastly, the single T3SS of Xanthomonas albilineans also belongs to the Inv/Mxi/Spa type T3SSs (Marguerettaz et al., 2011; Figures 1, 4). Although its role is yet unknown, functional analysis provided evidence that it is not required for virulence in plants.

Common to all atypical T3SSs, except those of $P$. viridiflava and B. elkanii, is the lack of genes coding for the wellcharacterized transcriptional regulators, structural components of pili, effector proteins and have no apparent role in plantmicrobe interactions. The similar features of these atypical T3SSs in bacteria with different lifestyles raise questions about their evolutionary origin and biological role. It is likely that they might be controlled by different regulatory networks than those controlling the T3SSs with a demonstrated role in plant-microbe interactions. These unusual T3SSs might secrete and/or translocate novel effectors exhibiting different features than those described for the well-characterized T3Es found in typical T3SSs. By analogy, surface appendages composed of different proteins might be made by these T3SSs. Remarkably, the so far characterized T3SS pili of both phytopathogenic bacteria and rhizobia consist of proteins with low or no homology to each other. Alternatively, these T3SSs may not form extracellular appendages ("needle-less" T3SS) similar to pili but they may be used only for extracellular secretion instead of effector translocation into other cells. Future studies are needed to shed light on the above issues and on the evolutionary mechanisms that have driven the acquisition and maintenance of these T3SSs in both pathogenic and symbiotic bacteria as well as to determine their role during their life cycles.

\section{CONCLUDING REMARKS}

The availability of an increasing number of genomes from T3SScontaining bacteria have unveiled an incredible diversity and complexity of T3SSs thus providing the opportunity and the challenge to better understand how this sophisticated secretion mechanism has evolved and adapted to fulfil the specific requirements of diverse bacterial species. The newly discovered systems provide the framework to define the similarities and differences of T3SSs that shape diverse biotic interactions. To date, most type III secretion research has focused on pathogenic bacteria, while few efforts have been made in symbiotic bacteria. Although rhizobial T3SSs contain most of the core type III components, the diversifications observed in members of some T3S protein families suggest that the structure and regulation of rhizobial secretion machineries have possibly adopted specific adaptations to serve the association of rhizobia with legume roots. Uncovering the specific structural and secretion regulatory components in various types of T3SSs will increase our knowledge about the mechanisms underlying the structure and function of T3SSs across phylogenetically diverse bacteria. An interesting avenue for further research will be the delineation of the T3S regulons in both phytopathogenic bacteria and rhizobia. The absence of well-known regulatory elements from various types of T3SS gene clusters denotes that transcriptional factors and cis-elements different from the so far known may be involved in controlling gene expression. On the other hand the presence of conserved ciselements upstream of genes with no apparent relation with the T3SS implies that these genes may be co-regulated. Next generation transcriptomics promises to provide new insights into the well-known transcriptional networks that govern type III secretion.

Furthermore, the presence of novel non-canonical T3SSs with yet unknown roles in both pathogenic and symbiotic bacteria opens new avenues in T3SS research hoping to reveal fascinating strategies exploited by the bacteria to interact with their biotic environment. Study of these T3SSs may help uncover new facets of their role in the interactions with plant and nonplant hosts. Future research efforts should be directed to defining the signaling circuits that control the expression of the atypical T3SSs. Deciphering the regulatory networks will be key to the future development of novel functional assays for screening and characterizing novel effectors.

Finally, a comprehensive understanding of T3SS structure and function in diverse bacteria is expected to illuminate various aspects of pathogenesis and symbiosis related with the evolution of T3SSs in bacteria with different lifestyles and the molecular mechanisms underlying plant-microbe interactions and beyond. Moreover, this knowledge will contribute in the development of various biotechnological applications involving the design of efficient strategies to control plant diseases, the exploitation of T3SS as scaffold for protein delivery into eukaryotic cells, the improvement of the symbiotic properties of rhizobial species or even the expansion of the symbiotic potential toward non-leguminous plants of agriculture importance. 


\section{ACKNOWLEDGMENTS}

I would like to apologize to those researchers whose work was not included in this review due to space limitations. I also thank the editors and three reviewers for their constructive criticisms and suggestions.

\section{REFERENCES}

Abby, S. S., and Rocha, E. P. (2012). The non-flagellar type III secretion system evolved from the bacterial flagellum and diversified into host-cell adapted systems. PLoS Genet. 8:e1002983. doi: 10.1371/journal.pgen.1002983

Alavi, S. M., Sanjari, S., Durand, F., Brin, C., Manceau, C., and Poussier, S. (2008). Assessment of the genetic diversity of Xanthomonas axonopodis pv. phaseoli and Xanthomonas fuscans subsp. fuscans as a basis to identify putative pathogenicity genes and a type III secretion system of the SPI- 1 family by multiple suppression subtractive hybridizations. Appl. Environ. Microbiol. 74, 3295-3301. doi: 10.1128/AEM.02507-07

Alfano, J. R., Charkowski, A. O., Deng, W. L., Badel, J. L., Petnicki-Ocwieja, T., van Dijk, K., et al. (2000). The Pseudomonas syringae Hrp pathogenicity island has a tripartite mosaic structure composed of a cluster of type III secretion genes bounded by exchangeable effector and conserved effector loci that contribute to parasitic fitness and pathogenicity in plants. Proc. Natl. Acad. Sci. U.S.A. 97, 4856-4861. doi: 10.1073/pnas.97.9.4856

Alfano, J. R., and Collmer, A. (1997). The type III (Hrp) secretion pathway of plant pathogenic bacteria: trafficking harpins, Avr proteins and death. J. Bacteriol. 179, 5655-5662.

Amadou, C., Pascal, G., Mangenot, S., Glew, M., Bontemps, C., Capela, D., et al. (2008). Genome sequence of the beta-rhizobium Cupriavidus taiwanensis and comparative genomics of rhizobia. Genome Res. 18, 1472-1483. doi: 10.1101/gr.076448.108

Araki, H., Tian, D., Goss, E. M., Jakob, K., Halldorsdottir, S. S., Kreitman, M., et al. (2006). Presence/absence polymorphism for alternative pathogenicity islands in Pseudomonas viridiflava, a pathogen of Arabidopsis. Proc. Natl. Acad. Sci. U.S.A. 103, 5887-5892. doi: 10.1073/pnas.0601431103

Ausmees, N., Kobayashi, H., Deakin, W. J., Marie, C., Krishnan, H. B., Broughton, W. J., et al. (2004). Characterization of NopP, a type III secreted effector of Rhizobium sp. strain NGR234. J. Bacteriol. 186, 4774-4780. doi: 10.1128/JB.186.14.4774-4780.2004

Bakkou, N., and Perret, X. (2008). "Functional analysis of a second type III secretion system in Rhizobium sp. NGR234," in Abstract book of the Eighth European Nitrogen Fixation Conference, (Ghent, Belgium), 209.

Baltrus, D. A., Nishimura, M. T., Romanchuk, A., Chang, J. H., Mukhtar, M. S., Cherkis, K., et al. (2011). Dynamic evolution of pathogenicity revealed by sequencing and comparative genomics of 19 Pseudomonas syringae isolates. PLoS Pathog. 7:e1002132. doi: 10.1371/journal.ppat.1002132

Barret, M., Egan, F., Moynihan, J., Morrissey, J. P., Lesouhaitier, O., and O'Gara, F. (2013). Characterization of the SPI-1 and Rsp type three secretion systems in Pseudomonas fluorescens F113. Environ. Microbiol. Rep. 5, 377-386. doi: 10.1111/1758-2229.12039.

Bartsev, A. V., Boukli, N. M., Deakin, W. J., Staehelin, C., and Broughton, W. J. (2003). Purification and phosphorylation of the effector protein NopL from Rhizobium sp. NGR234. FEBS Lett. 554, 271-274. doi: 10.1016/S00145793(03)01145-1

Bartsev, A. V., Deakin, W. J., Boukli, N. M., McAlvin, C. B., Stacey, G., Malnoë, P., et al. (2004). NopL, an effector protein of Rhizobium sp. NGR234, thwarts activation of plant defense reactions. Plant Physiol. 134, 871-879. doi: 10.1104/pp.103.031740

Bocsanczy, A. M., Nissinen, R. M., Oh, C. S., and Beer, S. V. (2008). HrpN of Erwinia amylovora functions in the translocation of DspA/E into plant cells. Mol. Plant Pathol. 9, 425-434. doi: 10.1111/j.1364-3703.2008.00471.x

Boller, T., and Felix, G. (2009). A renaissance of elicitors: perception of microbe-associated molecular patterns and danger signals by patternrecognition receptors. Annu. Rev. Plant Biol. 60, 379-406. doi: 10.1146/annurev.arplant.57.032905.105346

Brown, S. D., Utturkar, S. M., Klingeman, D. M., Johnson, C. M., Martin, S. L., Land, M, L., et al. (2012). Twenty-one genome sequences from Pseudomonas species and 19 genome sequences from diverse bacteria isolated from the rhizosphere and endosphere of Populus deltoides. J. Bacteriol. 194, 5991-5993. doi: 10.1128/JB.01243-12
Büttner, D. (2012). Protein export according to schedule: architecture, assembly, and regulation of type III secretion systems from plant- and animal-pathogenic bacteria. Microbiol. Mol. Biol. Rev. 76, 262-310. doi: 10.1128/MMBR.05017-11

Büttner, D., and He, S. Y. (2009). Type III protein secretion in plant pathogenic bacteria. Plant Physiol. 150, 1656-1664. doi: 10.1104/pp.109.139089

Büttner, D., Nennstiel, D., Klüsener, B., and Bonas, U. (2002). Functional analysis of HrpF, a putative type III translocon protein from Xanthomonas campestris pv vesicatoria. J. Bacteriol. 184, 2389-2398. doi: 10.1128/JB.184.9.2389-2398.2002

Caldelari Baumberger, I., Fraefel, N., Göttfert, M., and Hennecke, H. (2003). New NodW- or NifA-regulated Bradyrhizobium japonicum genes. Mol. Plant Microbe Interact. 16, 342-351. doi: 10.1094/MPMI.2003.16.4.342

Charity, J. C., Pak, K., Delwiche, C. F., and Hutcheson, S. W. (2003). Novel exchangeable effector loci associated with the Pseudomonas syringae $h r p$ pathogenicity island: evidence for integron-like assembly from transposed gene cassettes. Mol. Plant Microbe Interact. 16, 495-507. doi: 10.1094/MPMI.2003.16.6.495

Charkowski, A. O., Alfano, J. R., Preston, G., Yuan, J., He, S. Y., and Collmer, A. (1998). The Pseudomonas syringae pv. tomato $\mathrm{HrpW}$ protein has domains similar to harpins and pectate lyases and can elicit the plant hypersensitive response and bind to pectate. J. Bacteriol. 180, 5211-5217.

Chauhan, A., Layton, A. C., Williams, D. E., Smartt, A. E., Ripp, S., Karpinets, T. V., et al. (2011). Draft genome sequence of the polycyclic aromatic hydrocarbondegrading, genetically engineered bioluminescent bioreporter Pseudomonas fluorescens HK44. J. Bacteriol. 193, 5009-5010. doi: 10.1128/JB.05530-11

Choi, M. S., Kim, W., Lee, C., and Oh, C. S. (2013). Harpins, multifunctional proteins secreted by Gram-negative plant-pathogenic bacteria. Mol. Plant Microbe Interact. 26, 1115-1122. doi: 10.1094/MPMI-02-13-0050-CR

Clarke, C. R., Cai, R., Studholme, D. J., Guttman, D. S., and Vinatzer, B. A. (2010). Pseudomonas syringae strains naturally lacking the classical P. syringae $\mathrm{hrp} / \mathrm{hrc}$ locus are common leaf colonizers equipped with an atypical type III secretion system. Mol. Plant Microbe Interact. 23, 198-210. doi: 10.1094/MPMI-23-2-0198

Correa, V. R., Majerczak, D. R., Ammar, E.-D., Merighi, M., Pratt, R. C., Hogenhout, S. A., et al. (2012). The bacterium Pantoea stewartii uses two different type III secretion systems to colonize its plant host and insect vector. Appl. Environ. Microbiol. 78, 6327-6336. doi: 10.1128/AEM.00892-12

Cunnac, S., Boucher, C., and Genin, S. (2004). Characterization of the cis-acting regulatory element controlling HrpB-mediated activation of the type III secretion system and effector genes in Ralstonia solanacearum. J. Bacteriol. 186, 2309-2318. doi: 10.1128/JB.186.8.2309-2318.2004

Cusano, A. M., Burlinson, P., Deveau, A., Vion, P., Uroz, S., Preston, G. M., et al. (2011). Pseudomonas fluorescens BBc6R8 type III secretion mutants no longerpromote ectomycorrhizal symbiosis. Environ. Microbiol. Rep. 3, 203-210. doi: 10.1111/j.1758-2229.2010.00209.x

Dale, C., Young, S. A., Haydon, D. T., and Welburn, S. C. (2001). The insect endosymbiont Sodalis glossinidius utilizes a type III secretion system for cell invasion. Proc. Natl. Acad. Sci. U.S.A. 98, 1883-1888. doi: 10.1073/pnas.98.4.1883

Deakin, W. J., and Broughton, W. J. (2009). Symbiotic use of pathogenic strategies: rhizobial protein secretion systems. Nat. Rev. Microbiol. 7, 312-320. doi: 10.1038/nrmicro2091

Deakin, W. J., Marie, C., Saad, M. M., Krishnan, H. B., and Broughton, W. J. (2005). NopA is associated with cell surface appendages produced by the type III secretion system of Rhizobium sp. strain NGR234. Mol. Plant Microbe Interact. 18, 499-507. doi: 10.1094/MPMI-18-0499

de Lyra Mdo, C., Lopez-Baena, F. J., Madinabeitia, N., Vinardell, J. M., Espuny Mdel, R., Cubo, M. T., et al. (2006). Inactivation of the Sinorhizobium fredii HH103 rhcJ gene abolishes nodulation outer proteins (Nops) secretion and decreases the symbiotic capacity with soybean. Int. Microbiol. 9, 125-133.

Deng, W. L., Rehm, A. H., Charkowski, A. O., Rojas, C. M., and Collmer, A. (2003). Pseudomonas syringae exchangeable effector loci: sequence diversity in representative pathovars and virulence function in P. syringae pv. syringae B728a. J. Bacteriol. 185, 2592-602. doi: 10.1128/JB.185.8.2592-2602.2003

de Souza, J. A., Tieppo, E., Magnani Gde, S., Alves, L. M., Cardoso, R. L., Cruz, L. M., et al. (2012). Draft genome sequence of the nitrogen-fixing symbiotic bacterium Bradyrhizobium elkanii 587. J. Bacteriol. 194, 3547-3548. doi: 10.1128/JB.00563-12

Duan, J., Jiang, W., Cheng. Z., Heikkila, J. J., and Glick, B. R. (2013). The complete genome sequence of the plant growth-promoting bacterium Pseudomonas sp. UW4. PLoS ONE 8:e58640. doi: 10.1371/journal.pone.0058640 
Engelhardt, S., Lee, J., Gäbler, Y., Kemmerling, B., Haapalainen, M. L., Li, C. M., et al. (2009). Separable roles of the Pseudomonas syringae pv. phaseolicola accessory protein $\mathrm{HrpZ1}$ in ion-conducting pore formation and activation of plant immunity. Plant J. 57, 706-717. doi: 10.1111/j.1365-313X.2008.03723.x

Fauvart, M., Verstraeten, N., Dombrecht, B., Venmans, R., Beullens, S., Heusdens, C., et al. (2009). Rhizobium etli $\mathrm{HrpW}$ is a pectin-degrading enzyme and differs from phytopathogenic homologues in enzymically crucial tryptophan and glycine residues. Microbiology 155, 3045-3054. doi: 10.1099/mic.0.027599-0

Freiberg, C., Fellay, R., Bairoch, A., Broughton, W. J., Rosenthal, A., and Perret, X. (1997). Molecular basis of symbiosis between Rhizobium and legumes. Nature 387, 394-401. doi: 10.1038/387394a0

Gaudriault, S., Brisset, M. N., and Barny, M. A. (1998). HrpW of Erwinia amylovora, a new Hrp-secreted protein. FEBS Lett. 428, 224-228. doi: 10.1016/S0014-5793(98)00534-1

Gazi, A. D., Sarris, P. F., Fadouloglou, V. E., Charova, S. N., Mathioudakis, N., Panopoulos, N. J., et al. (2012). Phylogenetic analysis of a gene cluster encoding an additional, rhizobial-like type III secretion system that is narrowly distributed among Pseudomonas syringae strains. BMC Microbiol. 12:188. doi 10.1186/1471-2180-12-188

Giraud, E., Moulin, L., Vallenet, D., Barbe, V., Cytryn, E., Avarre, J. C., et al. (2007) Legumes symbioses: absence of Nod genes in photosynthetic bradyrhizobia. Science 316, 1307-1312. doi: 10.1126/science.1139548

González, V., Santamaría, R. I., Bustos, P., Hernández-González, I., Medrano-Soto, A., Moreno-Hagelsieb, G., et al. (2006). The partitioned Rhizobium etli genome: genetic and metabolic redundancy in seven interacting replicons. Proc. Natl. Acad. Sci. U.S.A. 103, 3834-3839. doi: 10.1073/pnas.0508502103

Göttfert, M., Röthlisberger, S., Kündig, C., Beck, C., Marty, R., and Hennecke, H. (2001). Potential symbiosis-specific genes uncovered by sequencing a 410-kilobase DNA region of the Bradyrhizobium japonicum chromosome. J. Bacteriol. 183, 1405-1412. doi: 10.1128/JB.183.4.1405-1412.2001

Green, S., Studholme, D. J., Laue, B. E., Dorati, F., Lovell, H., Arnold, D., et al. (2010). Comparative genome analysis provides insights into the evolution and adaptation of Pseudomonas syringae pv. aesculi on Aesculus hippocastanum. PLoS ONE 5:e10224. doi: 10.1371/journal.pone.0010224

Guttman, D. S., Gropp, S. J., Morgan, R. L., and Wang, P. W. (2006). Diversifying selection drives the evolution of the type III secretion system pilus of Pseudomonas syringae. Mol. Biol. Evol. 23, 2342-2354. doi: 10.1093/molbev/msl103

Gyaneshwar, P., Hirsch, A. M., Moulin, L., Chen, W. M., Elliott, G. N., Bontemps, C., et al. (2011). Legume-nodulating betaproteobacteria: diversity, host range, and future prospects. Mol. Plant Microbe Interact. 24, 1276-1288. doi: 10.1094/MPMI-06-11-0172

Hansen-Wester, I., and Hensel, M. (2001). Salmonella pathogenicity islands encoding type III secretion systems. Microbes Infect. 3, 549-559. doi: 10.1016/S12864579(01)01411-3

He, S. Y., Nomura, K., and Whittam. T. S. (2004). Type III protein secretion mechanism in mammalian and plant pathogens. Biochim. Biophys. Acta 1694 181-206. doi: 10.1016/j.bbamcr.2004.03.011

Hempel, J., Zehner, S., Göttfert, M., and Patschkowski, T. (2009). Analysis of the secretome of the soybean symbiont Bradyrhizobium japonicum. J. Biotechnol. 140, 51-58. doi: 10.1016/j.jbiotec.2008.11.002

Hojo, H., Koyanagi, M., Tanaka, M., Kajihara, S., Ohnishi, K., Kiba, A., et al. (2008). The hrp genes of Pseudomonas cichorii are essential for pathogenicity on eggplant but not on lettuce. Microbiology 154, 2920-2928. doi: 10.1099/mic.0.2008/021097-0

Hueck, C. J. (1998). Type III protein secretion systems in bacterial pathogens of animals and plants. Microbiol. Mol. Biol. Rev. 62, 379-433.

Huguet, E., and Bonas, U. (1997). hrpF of Xanthomonas campestris pv. vesicatoria encodes an $87-\mathrm{kDa}$ protein with homology to NolX of Rhizobium fredii. Mol. Plant Microbe Interact. 10, 488-498. doi: 10.1094/MPMI.1997.10.4.488

Hwang, M. S., Morgan, R. L., Sarkar, S. F., Wang, P. W., and Guttman, D. S. (2005). Phylogenetic characterization of virulence and resistance phenotypes of Pseudomonas syringae. Appl. Environ. Microbiol. 71, 5182-5191. doi: 10.1128/AEM.71.9.5182-5191.2005

Jackson, R. W., Preston, G. M., and Rainey, P. B. (2005). Genetic characterization of Pseudomonas fluorescens SBW25 rsp gene expression in the phytosphere and in vitro. J. Bacteriol. 187, 8477-8488. doi: 10.1128/JB.187.24.8477-8488.2005

Jiang, G., and Krishnan, H. B. (2000). Sinorhizobium fredii USDA257, a cultivarspecific soybean symbiont, carries two copies of $y 4 y A$ and $y 4 y B$, two open reading frames that are located in a region that encodes the type III protein secretion system. Mol. Plant Microbe Interact. 13, 1010-1014. doi: 10.1094/MPMI.2000.13.9.1010

Jin, Q., Hu, W., Brown, I., McGhee, G., Hart, P., Jones, A. L., et al. (2001) Visualization of secreted Hrp and Avr proteins along the Hrp pilus during type III secretion in Erwinia amylovora and Pseudomonas syringae. Mol. Microbiol. 40, 1129-1139. doi: 10.1046/j.1365-2958.2001.02455.x

Joardar, V., Lindeberg, M., Jackson, R. W., Selengut, J., Dodson, R., Brinkac, L. M., et al. (2005). Whole-genome sequence analysis of Pseudomonas syringae pv. phaseolicola 1448A reveals divergence among pathovars in genes involved in virulence and transposition. J. Bacteriol. 187, 6488-6498. doi: 10.1128/JB.187.18.6488-6498.2005

Journet, L., Agrain, C., Broz, P., and Cornelis, G. R. (2003). The needle length of bacterial injectisomes is determined by a molecular ruler. Science 302, 1757-1760. doi: 10.1126/science. 1091422

Kaneko, T., Nakamura, Y., Sato, S., Asamizu, E., Kato, T., Sasamoto, S., et al. (2000). Complete genome structure of the nitrogen-fixing symbiotic bacterium Mesorhizobium loti. DNA Res. 7, 331-338. doi: 10.1093/dnares/7.6.331

Kaneko, T., Nakamura, Y., Sato, S., Minamisawa, K., Uchiumi, T., Sasamoto, S., et al. (2002) Complete genomic sequence of nitrogen-fixing symbiotic bacterium Bradyrhizobium japonicum USDA110. DNA Res. 9, 189-197. doi: 10.1093/dnares/9.6.189

Kimbrel, J. A., Givan, S. A., Halgren, A. B., Creason, A. L., Mills, D. I., Banowetz, G. M., et al. (2010). An improved, high-quality draft genome sequence of the Germination-Arrest Factor-producing Pseudomonas fluorescens WH6. BMC Genomics 11:522. doi: 10.1186/1471-2164-11-522

Kimbrel, J. A., Thomas, W. J., Jiang, Y., Creason, A. L., Thireault, C. A., Sachs, J. L., et al. (2013). Mutualistic co-evolution of type III effector genes in Sinorhizobium fredii and Bradyrhizobium japonicum. PLoS Pathog. 9:e1003204. doi: 10.1371/journal.ppat.1003204

Kim, J. F., and Beer, S. V. (1998). HrpW of Erwinia amylovora, a new harpin that contains a domain homologous to pectate lyases of a distinct class. J. Bacteriol. $180,5203-5210$.

Kim, W. S., and Krishnan, H. B. (2014). A nopA deletion mutant of Sinorhizobium fredii USDA257, a soybean symbiont, is impaired in nodulation. Curr. Microbiol. 68, 239-246. doi 10.1007/s00284-013-0469-4

Kovács, L. G., Balatti, P. A., Krishnan, H. B., and Pueppke, S. G. (1995) Transcriptional organisation and expression of nolXWBTUV, a locus that regulates cultivar-specific nodulation of soybean by Rhizobium fredii USDA257. Mol. Microbiol. 17, 923-933. doi: 10.1111/j.1365-2958.1995.mmi_17050923.x

Krause, A., Doerfel, A., and Göttfert, M. (2002). Mutational and transcriptional analysis of the type III secretion system of Bradyrhizobium japonicum. Mol. Plant Microbe Interact. 15, 1228-1235. doi: 10.1094/MPMI.2002.15.12.1228

Krishnan, H. B. (2002). NolX of Sinorhizobium fredii USDA257, a type III-secreted protein involved in host range determination, is localized in the infection threads of cowpea (Vigna unguiculata [L.] Walp) and soybean (Glycine max [L.] Merr.) nodules. J. Bacteriol. 184, 831-839. doi: 10.1128/JB.184.3.831-839.2002

Krishnan, H. B., Lorio, J., Kim, W. S., Jiang, G., Kim, K. Y., DeBoer, M., et al. (2003). Extracellular proteins involved in soybean cultivar-specific nodulation are associated with pilus-like surface appendages and exported by a type III protein secretion system in Sinorhizobium fredii USDA257. Mol. Plant Microbe Interact. 16, 617-625. doi: 10.1094/MPMI.2003.16.7.617

Krishnan, H. B., Natarajan, S. S., and Kim, W. S. (2011). Distinct cell surface appendages produced by Sinorhizobium fredii USDA257 and S. fredii USDA191, cultivar-specific and nonspecific symbionts of soybean. Appl. Environ. Microbiol. 77, 6240-6248. doi: 10.1128/AEM.05366-11

Kvitko, B. H., Ramos, A. R., Morello, J. E., Oh, H. S., and Collmer, A. (2007). Identification of harpins in Pseudomonas syringae pv. tomato DC3000, which are functionally similar to HrpK1 in promoting translocation of type III secretion system effectors. J. Bacteriol. 189, 8059-8072. doi: 10.1128/JB. 01146-07

Kube, M., Migdoll, A. M., Gehring, I., Heitmann, K., Mayer, Y., Kuhl, H., et al. (2010). Genome comparison of the epiphytic bacteria Erwinia billingiae and E. tasmaniensis with the pear pathogen E. pyrifoliae. BMC Genomics 11:393, doi: 10.1186/1471-2164-11-393

Kube, M., Migdoll, A. M., Müller, I., Kuhl, H., Beck, A., Reinhardt, R., et al. (2008). The genome of Erwinia tasmaniensis strain Et1/99, a non-pathogenic bacterium in the genus Erwinia. Environ. Microbiol. 10, 2211-2222. doi: 10.1111/j.14622920.2008.01639.x 
Lee, J., Klusener, B., Tsiamis, G., Stevens, C., Neyt, C., Tampakaki, A. P., et al. (2001). HrpZ(Psph) from the plant pathogen Pseudomonas syringae pv. phaseolicola binds to lipid bilayers and forms an ion-conducting pore in vitro. Proc. Natl. Acad. Sci. U.S.A. 98, 289-294. doi: 10.1073/pnas.98.1.289

Lee, Y. H., Kolade, O. O., Nomura, K., Arvidson, D. N., and He, S. Y. (2005). Use of dominant-negative HrpA mutants to dissect Hrp pilus assembly and type iii secretion in Pseudomonas syringae pv. tomato. J. Biol. Chem. 280, 21409-21417. doi: 10.1074/jbc.M500972200

Lefort, F., Calmin, G., Crovadore, J., Osteras, M., and Farinelli, L. (2013). Whole-genome shotgun sequence of Pseudomonas viridiflava, a bacterium species pathogenic to Arabidopsis thaliana. Genome Announc. 1:e00116-12. doi: 10.1128/genomeA.00116-12

Li, J. G., Liu, H. X., Cao, J., Chen, L. F., Gu, C., Allen, C., et al. (2010). PopW of Ralstonia solanacearum, a new two-domain harpin targeting the plant cell wall. Mol. Plant Pathol. 11, 371-381. doi: 10.1111/j.1364-3703.2010.00610.x

Li, Y., Tian, C. F., Chen, W. F., Wang, L., Sui, X. H., and Chen, W. X. (2013). High-resolution transcriptomic analyses of Sinorhizobium sp. NGR234 bacteroids in determinate nodules of Vigna unguiculata and indeterminate nodules of Leucaena leucocephala. PLoS ONE 8:e70531. doi: 10.1371/journal.pone. 0070531

Lindeberg, M., Myers, C. R., Collmer, A., and Schneider, D. J. (2008). Roadmap to new virulence determinants in Pseudomonas syringae: Insights from comparative genomics and genome organization. Mol. Plant Microbe Interact. 21, 685-700. doi: 10.1094/MPMI-21-6-0685

Lindström, K., and Young, J. P. (2011). International Committee on Systematics of Prokaryotes Subcommittee on the taxonomy of Agrobacterium and Rhizobium: minutes of the meeting, 7 September 2010, Geneva, Switzerland. Int. J. Syst. Evol. Microbiol. 61(Pt 12), 3089-3093. doi: 10.1099/ijs.0.036913-0

Loper, J. E., Hassan, K. A., Mavrodi, D. V., Davis, E. W., 2nd., Lim, C. K., Shaffer, B. T., et al. (2012). Comparative genomics of plant-associated Pseudomonas spp.: insights into diversity and inheritance of traits involved in multitrophic interactions. PLoS Genet. 8:e1002784. doi: 10.1371/journal.pgen.1002784

López-Baena, F. J., Monreal, J. A., Pérez-Montaño, F., Guasch-Vidal, B., Bellogín, R. A., Vinardell, J. M., et al. (2009). The absence of Nops secretion in Sinorhizobium fredii $\mathrm{HH} 103$ increases GmPR1 expression in Williams soybean. Mol. Plant Microbe Interact. 22, 1445-1454. doi: 10.1094/MPMI-22-11-1445.

López-Baena, F. J., Vinardell, J. M., Pérez-Montaño, F., Crespo-Rivas, J. C., Bellogín, R. A., Espuny Mdel, R., et al. (2008). Regulation and symbiotic significance of nodulation outer proteins secretion in Sinorhizobium fredii HH103. Microbiology 154, 1825-1836. doi: 10.1099/mic.0.2007/016337-0

Lorio, J. C., Chronis, D., and Krishnan, H. B. (2006). Y4xP, an open reading frame located in a type III protein secretion system locus of Sinorhizobium fredii USDA257 and USDA191, encodes cysteine synthase. Mol. Plant Microbe Interact. 19, 635-643. doi: 10.1094/MPMI-19-0635

Lorio, J. C., Kim, W. S., and Krishnan, H. B. (2004). NopB, a soybean cultivar-specificity protein from Sinorhizobium fredii USDA257, is a type III secreted protein. Mol. Plant Microbe Interact. 17, 1259-1268. doi: 10.1094/MPMI.2004.17.11.1259

Maketon, C., Fortuna, A. M., and Okubara, P. A. (2012). Cultivar-dependent transcript accumulation in wheat roots colonized by Pseudomonas fluorescens Q8r1-96 wild type and mutant strains. Biol. Control 60, 216-224. doi: 10.1016/j.biocontrol.2011.11.002

Margaret, I., Becker, A., Blom, J., Bonilla, I., Goesmann, A., Göttfert, M., et al. (2011). Symbiotic properties and first analyses of the genomic sequence of the fast growing model strain Sinorhizobium fredii HH103 nodulating soybean. J. Biotechnol. 155, 11-19. doi: 10.1016/j.jbiotec.2011.03.016

Marguerettaz, M., Pieretti, I., Gayral, P., Puig, J., Brin, C., Cociancich, S., et al. (2011). Genomic and evolutionary features of the SPI-1 type III secretion system that is present in Xanthomonas albilineans but is not essential for xylem colonization and symptom development of sugarcane leaf scald. Mol. Plant Microbe Interact. 24, 246-259 doi: 10.1094/MPMI-08-10-0188

Marie, C., Broughton, W. J., and Deakin, W. J. (2001). Rhizobium type III secretion systems: legume charmers or alarmers? Curr. Opin. Plant Biol. 4, 336-342. doi: 10.1016/S1369-5266(00)00182-5

Marie, C., Deakin, W. J., Ojanen-Reuhs, T., Diallo, E., Reuhs, B., Broughton W. J., et al. (2004). TtsI, a key regulator of Rhizobium species NGR234 is required for type III-dependent protein secretion and synthesis of rhamnose-rich polysaccharides. Mol. Plant Microbe Interact. 17, 958-966. doi: 10.1094/MPMI.2004.17.9.958
Marie, C., Deakin, W. J., Viprey, V., Kopciñska, J., Golinowski, W., Krishnan, H. B., et al. (2003). Characterization of Nops, nodulation outer proteins, secreted via the type III secretion system of NGR234. Mol. Plant Microbe Interact. 16, 743-751. doi: 10.1094/MPMI.2003.16.9.743

Martínez-Abarca, F., Martínez-Rodríguez, L., Lüpez-Contreras, J. A., JiménezZurdo, J. I., and Toro, N. (2013). Complete genome sequence of the alfalfa symbiont Sinorhizobium/Ensifer meliloti Strain GR4. Genome Announc. 2013, pii:e00174-12.

Masson-Boivin, C., Giraud, E., Perret, X., and Batut, J. (2009). Establishing nitrogen-fixing symbiosis with legumes: How many rhizobium recipes? Trends Microbiol. 17, 458-466. doi: 10.1016/j.tim.2009.07.004

Mathimaran, N., Srivastava, R., Wiemken, A., Sharma, A. K., and Boller, T. (2012). Genome sequences of two plant growth-promoting fluorescent Pseudomonas strains, R62 and R81. J. Bacteriol. 194, 3272-3273. doi: 10.1128/JB.00349-12

Mavrodi, D. V., Joe, A., Mavrodi, O. V., Hassan, K. A., Weller, D. M., Paulsen, I. T., et al. (2011). Structural and functional analysis of the type III secretion system from Pseudomonas fluorescens Q8r1-96. J. Bacteriol. 193, 177-189. doi: 10.1128/JB.00895-10

Mazurier, S., Lemunier, M., Siblot, S., Mougel, C., and Lemanceau, P. (2004). Distribution and diversity of type III secretion system-like genes in saprophytic and phytopathogenic fluorescent pseudomonads. FEMS Micobiol. Ecol. 4, 455-467. doi: 10.1016/j.femsec.2004.04.019

Meyer, D. S., Cunnac, M., Gueneron, C., Declercq, F., Van Gijsegem, E., Lauber, C., et al. (2006). PopF1 and PopF2, two proteins secreted by the type III protein secretion system of Ralstonia solanacearum, are translocators belonging to the HrpF/NopX family. J. Bacteriol. 188, 4903-4917. doi: 10.1128/JB.00180-06

Mohr, T. J., Liu, H., Yan, S., Morris, C. E., Castillo, J. A., Jelenska, J., et al. (2008). Naturally occurring nonpathogenic isolates of the plant pathogen Pseudomonas syringae lack a type III secretion system and effector gene orthologues. J. Bacteriol. 190, 2858-2870. doi: 10.1128/JB.01757-07

Newman, M. A., Sundelin, T., Nielsen, J. T., and Erbs, G. (2013). MAMP (microbeassociated molecular pattern) triggered immunity in plants. Front. Plant Sci. 4:139. doi: 10.3389/fpls.2013.00139

O’Brien, H. E., Thakur, S., Gong, Y., Fung, P., Zhang, J., Yuan, L., et al. (2012). Extensive remodeling of the Pseudomonas syringae pv. avellanae type III secretome associated with two independent host shifts onto hazelnut. BMC Microbiol. 12:141. doi: 10.1186/1471-2180-12-141

O'Brien, H. E., Thakur, S., and Guttman, D. S. (2011). Evolution of plant pathogenesis in Pseudomonas syringae: a genomics perspective. Annu. Rev. Phytopathol. 49, 269-289. doi: 10.1146/annurev-phyto-072910-095242

Oh, C. S., and Beer, S. V. (2005). Molecular genetics of Erwinia amylovora involved in the development of fire blight. FEMS Microbiol. Lett. 253, 185-192. doi: 10.1016/j.femsle.2005.09.051

Okazaki, S., Okabe, S., Higashi, M., Shimoda, Y., Sato, S., Tabata, S., et al. (2010). Identification and functional analysis of type III effector proteins in Mesorhizobium loti. Mol. Plant Microbe Interact. 23, 223-234. doi: 10.1094/MPMI-23-2-0223

Okazaki, S., Kaneko, T., Sato, S., and Saeki, K. (2013). Hijacking of leguminous nodulation signaling by the rhizobial type III secretion system. Proc. Natl. Acad. Sci. U.S.A. 110, 17131-17136. doi: 10.1073/pnas.1302360110

Okazaki, S., Zehner, S., Hempel, J., Lang, K., and Göttfert, M. (2009). Genetic organization and functional analysis of the type III secretion system of Bradyrhizobium elkanii. FEMS Microbiol. Lett. 295, 88-95. doi: 10.1111/j.15746968.2009.01593.x

Partida-Martínez, L. P., and Heil, M. (2011). The microbe-free plant: fact or artifact? Front. Plant Sci. 2:100. doi: 10.3389/fpls.2011.00100

Patel, H. K., da Silva, D. P., Devescovi, G., Maraite, H., Paszkiewicz, K., Studholme, D. J., et al. (2012). Draft genome sequence of Pseudomonas fuscovaginae, a broad-host-range pathogen of plants. J. Bacteriol. 194, 2765-2766. doi: 10.1128/JB.00341-12

Perret, X., Freiberg, C., Rosenthal, A., Broughton, W. J., and Fellay, R. (1999). Highresolution transcriptional analysis of the symbiotic plasmid of Rhizobium sp. NGR234. Mol. Microbiol. 32, 415-425. doi: 10.1046/j.1365-2958.1999.01361.x

Perret, X., Kobayashi, H., and Collado-Vides, J. (2003). Regulation of expression of symbiotic genes in Rhizobium sp. NGR234. Indian J. Exp. Biol. 41, 1101-1113.

Petnicki-Ocwieja, T., van Dijk, K., and Alfano, J. R. (2005). The hrpK operon of Pseudomonas syringae pv. tomato DC3000 encodes two proteins secreted by the type III (Hrp) protein secretion system: HopB1 and HrpK, a putative type III translocator. J. Bacteriol. 187, 649-663. doi: 10.1128/JB.187.2.649-663.2005 
Pieretti, I., Royer, M., Barbe, V., Carrere, S., Koebnik, R., Cociancich, S., et al. (2009). The complete genome sequence of Xanthomonas albilineans provides new insights into the reductive genome evolution of the xylem-limited Xanthomonadaceae. BMC Genomics 10:616. doi: 10.1186/1471-2164-10-616

Preston, G. M., Bertrand, N., and Rainey, P. B. (2001). Type III secretion in plant growth-promoting Pseudomonas fluorescens SBW25. Mol. Microbiol. 41, 999-1014. doi: 10.1046/j.1365-2958.2001.02560.x

Qi, M., Wang, D., Bradley, C. A., and Zhao, Y. (2011). Genome sequence analyses of Pseudomonas savastanoi pv. glycinea and subtractive hybridization-based comparative genomics with nine pseudomonads. PLoS ONE 6:e16451. doi: 10.1371/journal.pone.0016451

Park, J. Y., Han, S. H., Lee, J. H., Han, Y. S., Lee, Y. S., Rong, X., et al. (2011) Draft genome sequence of the biocontrol bacterium Pseudomonas putida B001, an oligotrophic bacterium that induces systemic resistance to plant diseases. J. Bacteriol. 193, 6795-6796. doi: 10.1128/JB.06217-11

Racape, J., Belbahri, L., Engelhardt, S., Lacombe, B., Lee, J., Lochman, J., et al. (2005). Ca2+-dependent lipid binding and membrane integration of PopA, a harpin-like elicitor of the hypersensitive response in tobacco. Mol. Microbiol. 58, 1406-1420. doi: 10.1111/j.1365-2958.2004.04910.x

Rainbow, L., Hart, C. A., and Winstanley, C. (2002). Distribution of type III secretion gene clusters in Burkholderia pseudomallei, B. thailandensis and B. mallei. J. Med. Microbiol. 51, 374-384.

Redondo-Nieto, M., Barret, M., Morrisey, J., Germaine, K., Martinez-Granero, F., Barahona, E., et al. (2013). Genome sequence reveals that Pseudomonas fluorescens $\mathrm{F} 113$ possesses a large and diverse array of systems for rhizosphere function and host interaction. BMC Genomics 14:54. doi: 10.1186/1471-216414-54

Redondo-Nieto, M., Barret, M., Morrisey, J. P., Germaine, K., MartínezGranero, F., Barahona, E., et al. (2012). Genome sequence of the biocontrol strain Pseudomonas fluorescens F113. J. Bacteriol. 194, 1273-1274. doi: 10.1128/JB.06601-11

Reinhardt, J. A., Baltrus, D. A., Nishimura, M. T., Jeck, W. R., Jones, C. D., and Dangl, J. L. (2009). De novo assembly using low-coverage short read sequence data from the rice pathogen Pseudomonas syringae pv. oryzae. Genome Res. 19 294-305. doi: 10.1101/gr.083311.108

Rezzonico, F., Défago, G., and Moënne-Loccoz, Y. (2004). Comparison of ATPaseencoding type III secretion system $h r c N$ genes in biocontrol fluorescent pseudomonads and in phytopathogenic proteobacteria. Appl. Environ. Microbiol. 70 5119-5131. doi: 10.1128/AEM.70.9.5119-5131.2004

Rezzonico, F. C., Binder, C., Defago G., and Moenne-Loccoz, Y. (2005). The type III secretion system of biocontrol Pseudomonas fluorescens KD targets the phytopathogenic Chromista Pythium ultimum and promotes cucumber protection. Mol. Plant Microbe Interact. 18, 991-1001. doi: 10.1094/MPMI-18-0991

Rivas, S., and Genin, S. (2011). A plethora of virulence strategies hidden behind nuclear targeting of microbial effectors. Front. Plant Sci. 2:104. doi 10.3389/fpls.2011.00104

Rodrigues, J. A., López-Baena, F. J., Ollero, F. J., Vinardell, J. M., Espuny, M. R., Bellogín, R. A., et al. (2007). NopM and NopD are rhizobial nodulation outer proteins: identification using LC-MALDI and LC-ESI with a monolithic capillary column. J. Proteome Res. 6, 1029-1037. doi: 10.1021/pr060519f

Rodríguez-Palenzuela, P., Matas, I. M., Murillo, J., López-Solanilla, E., Bardaji, L., Pérez-Martínez, I., et al. (2010). Annotation and overview of the Pseudomonas savastanoi pv. savastanoi NCPPB 3335 draft genome reveals the virulence gene complement of a tumour-inducing pathogen of woody hosts. Environ. Microbiol. 12, 1604-1620. doi: 10.1111/j.1462-2920.2010.02207.x

Roine, E., Wei, W., Yuan, J., Nurmiaho-Lassila, E. L., Kalkkinen, N., Romantschuk, M., et al. (1997). Hrp pilus: an $h r p$-dependent bacterial surface appendage produced by Pseudomonas syringae pv. tomato DC3000. Proc. Natl. Acad. Sci. U.S.A. 94, 3459-3464. doi: 10.1073/pnas.94.7.3459

Saad, M. M., Crèvecoeur, M., Masson-Boivin, C., and Perret, X. (2012). The type 3 protein secretion system of Cupriavidus taiwanensis strain lmg19424 compromises symbiosis with Leucaena leucocephala. Appl. Environ. Microbiol. 78, 7476-7479. doi: 10.1128/AEM.01691-12

Saad, M. M., Kobayashi, H., Marie, C., Brown, I. R., Mansfield, J. W., Broughton, W. J., et al. (2005). NopB, a Type III Secreted Protein of Rhizobium sp. strain NGR234, is associated with pilus-like surface appendages. J. Bacteriol. 187, 1173-1181. doi: 10.1128/JB.187.3.1173-1181.2005

Saad, M. M., Staehelin, C., Broughton, W. J., and Deakin, W. J. (2008). Protein-protein interactions within type III secretion system-dependent pili of Rhizobium sp. strain NGR234. J. Bacteriol. 190, 750-754. doi: 10.1128/JB. 01116-07

Saeki, K. (2011). Rhizobial measures to evade host defense strategies and endogenous threats to persistent symbiotic nitrogen fixation: a focus on two legume-rhizobium model systems. Cell Mol. Life Sci. 68, 1327-1339. doi: 10.1007/s00018-011-0650-5

Sánchez, C., Iannino, F., Deakin, W. J., Ugalde, R. A., and Lepek, V. C. (2009). Characterization of the Mesorhizobium loti MAFF303099 type-three protein secretion system. Mol. Plant Microbe Interact. 22, 519-528. doi: 10.1094/MPMI22-5-0519

Schirrmeister, J., Friedrich, L., Wenzel, M., Hoppe, M., Wolf, C., Göttfert, M., et al. (2011). Characterization of the self-cleaving effector protein NopE1 of Bradyrhizobium japonicum. J. Bacteriol. 193, 3733-3739. doi: 10.1128/JB. 00437-11

Schmeisser, C., Liesegang, H., Krysciak, D., Bakkou, N., Le Quéré, A., Wollherr A., et al. (2009). Rhizobium sp. strain NGR234 possesses a remarkable number of secretion systems. Appl. Environ. Microbiol. 75, 4035-4045. doi: 10.1128/AEM.00515-09

Schuldes, J., Rodriguez Orbegoso, M., Schmeisser, C., Krishnan, H. B., Daniel, R., and Streit, W. R. (2012). Complete genome sequence of the broadhost-range strain Sinorhizobium fredii USDA257. J. Bacteriol. 194:4483. doi: 10.1128/JB.00966-12

Sebaihia, M., Bocsanczy, A. M., Biehl, B. S., Quail, M. A., Perna, N. T., Glasner, J. D., et al. (2010). Complete genome sequence of the plant pathogen Erwinia amylovora strain ATCC 49946. J. Bacteriol. 192, 2020-2021. doi: 10.1128/JB.00022-10

Setubal, J. C., Wood, D., Burr, T., Farrand, S. Godman, B., Goodner, B., et al. (2009) "The genomics of Agrobacterium: Insights into its pathogenicity, biocontol and evolution," in Plant Pathogenic Bacteria: Genomics and Molecular Biology., ed R. Jackson (Norfolk: Caister Academic Press), 91-112.

Silby, M. W., Cerdeño-Tárraga, A. M., Vernikos, G. S., Giddens, S. R., Jackson, R. W. Preston, G. M., et al. (2009). Genomic and genetic analyses of diversity and plant interactions of Pseudomonas fluorescens. Genome Biol. 10:R51. doi: 10.1186/gb2009-10-5-r51

Slater, S. C., Goldman, B. S., Goodner, B., Setubal, J. C., Farrand, S. K., Nester, E. W., et al. (2009). Genome sequences of three Agrobacterium biovars help elucidate the evolution of multichromosome genomes in bacteria. J. Bacteriol. 191, 2501-2511. doi: 10.1128/JB.01779-08

Smits, T. H., Jaenicke, S., Rezzonico, F., Kamber, T., Goesmann, A., Frey, J. E., et al (2010a). Complete genome sequence of the fire blight pathogen Erwinia pyrifoliae DSM 12163T and comparative genomic insights into plant pathogenicity. BMC Genomics 11:2. doi: 10.1186/1471-2164-11-2

Smits, T. H., Rezzonico, F., Kamber, T., Blom, J., Goesmann, A., Frey, J. E., et al. (2010b). Complete genome sequence of the fire blight pathogen Erwinia amylovora CFBP 1430 and comparison to other Erwinia spp. Mol. Plant Microbe Interact. 23, 384-393. doi: 10.1094/MPMI-23-4-0384

Soto, M. J., Sanjuán, J., and Olivares, J. (2006). Rhizobia and plant-pathogenic bacteria: common infection weapons. Microbiology 152(Pt 11), 3167-3174. doi: 10.1099/mic. $0.29112-0$

Stevens, M. P., Wood, M. W., Taylor, L. A., Monaghan, P., Hawes, P., Jones, P. W., et al. (2002). An Inv/Mxi-Spa-like type III protein secretion system in Burkholderia pseudomallei modulates intracellular behaviour of the pathogen. Mol. Microbiol. 46, 649-659. doi: 10.1046/j.1365-2958.2002.03190.x

Streit, W. R., Schmitz, R. A., Perret, X., Staehelin, C., Deakin, W. J., Raasch, C., et al. (2004). An evolutionary hot spot: The pNGR234b replicon of Rhizobium sp. strain NGR234. J. Bacteriol. 186, 535-542. doi: 10.1128/JB.186.2.535542.2004

Studholme, D. J., Ibanez, S. G., MacLean, D., Dangl, J. L., Chang, J. H., and Rathjen, J. P. (2009). A draft genome sequence and functional screen reveals the repertoire of type III secreted proteins of Pseudomonas syringae pathovar tabaci 11528. BMC Genomics. 10:395. doi: 10.1186/1471-2164-10-395

Sugawara, M., Epstein, B., Badgley, B. D., Unno, T., Xu, L., Reese, J., et al. (2013). Comparative genomics of the core and accessory genomes of 48 Sinorhizobium strains comprising five genospecies. Genome Biol. 14:R17. doi: 10.1186/gb-201314-2-r17

Tampakaki, A. P., Skandalis, N., Gazi, A. D., Bastaki, M. N., Sarris, P. F., Charova, S. N., et al. (2010). Playing the "Harp": evolution of our understanding of hrp/hrc genes. Annu. Rev. Phytopathol. 48, 347-370. doi: 10.1146/annurevphyto-073009-114407 
Tamura, K., Stecher, G., Peterson, D., Filipski, A., and Kumar, S. (2013). MEGA6: molecular evolutionary genetics analysis version 6.0. Mol. Biol. Evol. 30, 2725-2729. doi: 10.1093/molbev/mst197

Tian, C. F., Zhou, Y. J., Zhang, Y. M., Li, Q. Q., Zhang, Y. Z., Li, D. F., et al. (2012). Comparative genomics of rhizobia nodulating soybean suggests extensive recruitment of lineage-specific genes in adaptations. Proc. Natl. Acad. Sci. U.S.A. 109, 8629-8634. doi: 10.1073/pnas.1120436109

Torto-Alalibo, T., Collmer, C. W., Lindeberg, M., Bird, D., Collmer, A., and Tyler, B. M., (2009). Common and contrasting themes in host cell-targeted effectors from bacterial, fungal, oomycete and nematode plant symbionts described using the Gene Ontology. BMC Microbiol. 9(Suppl. 1):S3. doi: 10.1186/1471-2180-9S1-S3

Troisfontaines, P., and Cornelis, G. R. (2005). Type III secretion: more systems than you think. Physiology 20, 326-339. doi: 10.1152/physiol.00011.2005

Van Gijsegem, F., Vasse, J., Camus, J. C., Marenda, M., and Boucher, C. (2000). Ralstonia solanacearum produces $h r p$-dependent pili that are required for PopA secretion but not for attachment of bacteria to plant cells. Mol. Microbiol. 36, 249-260. doi: 10.1046/j.1365-2958.2000.01851.x

Viollet, A., Corberand, T., Mougel, C., Robin, A., Lemanceau, P., and Mazurier, S. (2011). Fluorescent pseudomonads harboring type III secretion genes are enriched in the mycorrhizosphere of Medicago truncatula. FEMS Microbiol. Ecol. 75, 457-467. doi: 10.1111/j.1574-6941.2010.01021.x

Viprey, V., Del Greco, A., Golinowski, W., Broughton, W. J., and Perret, X. (1998). Symbiotic implications of type III protein secretion machinery in Rhizobium. Mol. Microbiol. 28, 1381-1389. doi: 10.1046/j.1365-2958.1998.00920.x

Warmink, J. A., and van Elsas, J. D. (2008). Selection of bacterial populations in the mycosphere of Laccaria proxima: is type III secretion involved? ISME J. 2, 887-900. doi: 10.1038/ismej.2008.41

Wassem, R., Kobayashi, H., Kambara, K., Le Quéré, A., Walker, G. C., Broughton, W. J., et al. (2008). TtsI regulates symbiotic genes in Rhizobium species NGR234 by binding to tts boxes. Mol. Microbiol. 68, 736-748. doi: 10.1111/j.13652958.2008.06187.x

Weber, E., and Koebnik, R. (2005). Domain structure of HrpE, the Hrp pilus subunit of Xanthomonas campestris pv. vesicatoria. J. Bacteriol. 187, 6175-6186. doi: 10.1128/JB.187.17.6175-6186.2005

Weber, E., and Koebnik, R. (2006). Positive selection of the Hrp pilin HrpE of the plant pathogen Xanthomonas. J. Bacteriol. 188, 1405-1410. doi: 10.1128/JB.188.4.1405-1410.2006

Weber, E. T., Ojanen-Reuhs, E., Huguet, G., Hause, M., Romantschuk, T. K., Korhonen, U., et al. (2005). The type III-dependent Hrp pilus is required for productive interaction of Xanthomonas campestris pv.vesicatoria with pepper host plants. J. Bacteriol. 187, 2458-2468. doi: 10.1128/JB.187.7.24582468.2005

Weidner, S., Becker, A., Bonilla, I., Jaenicke, S., Lloret, J., Margaret, I., et al. (2012). Genome sequence of the soybean symbiont Sinorhizobium fredii HH103. J. Bacteriol. 194, 1617-1618. doi: 10.1128/JB.06729-11
Wenzel, M., Friedrich, L., Göttfert, M., and Zehner, S. (2010). The type III-secreted protein NopE1 affects symbiosis and exhibits a calcium-dependent autocleavage activity. Mol. Plant Microbe Interact. 23, 124-129. doi: 10.1094/MPMI-23-10124

Xiao, Y., Heu, S., Yi, J., Lu, Y., and Hutcheson, S. W. (1994). Identification of a putative alternate sigma factor and characterization of a multicomponent regulatory cascade controlling the expression of Pseudomonas syringae pv. syringae Pss61 hrp and hrmA genes. J. Bacteriol. 176, 1025-1036.

Xiao, Y., and Hutcheson, S. W. (1994). A single promoter sequence recognized by a newly identified alternate sigma factor directs expression of pathogenicity and host range determinants in Pseudomonas syringae. J. Bacteriol. 176, 3089-3091.

Xie, G., Cui, Z., Tao, Z., Qiu, H., Liu, H., Ibrahim, M., et al. (2012). Genome sequence of the rice pathogen Pseudomonas fuscovaginae CB98818. J. Bacteriol. 194, 5479-5480. doi: 10.1128/JB.01273-12

Yang, S., Tang, F., Gao, M. Q., Krishnan, H. B., and Zhu, H. Y. (2010a). R genecontrolled host specificity in the legume-rhizobia symbiosis. Proc. Natl. Acad. Sci. U.S.A. 107, 18735-18740. doi: 10.1073/pnas.1011957107

Yang, Y., Zhao, J., Morgan, R. L., Ma, W., and Jiang, T. (2010b). Computational prediction of type III secreted proteins from Gram-negative bacteria. BMC Bioinformatics 11(Suppl. 1):S47. doi: 10.1186/1471-2105-11-S1-S47

Zamioudis, C., and Pieterse, C. M. (2012). Modulation of host immunity by beneficial microbes. Mol. Plant Microbe Interact. 25, 139-150. doi: 10.1094/MPMI06-11-0179

Zehner, S., Schober, G., Wenzel, M., Lang, K., and Göttfert, M. (2008). Expression of the Bradyrhizobium japonicum type III secretion system in legume nodules and analysis of the associated $t$ ts box promoter. Mol. Plant-Microbe Interact. 21, 1087-1093. doi: 10.1094/MPMI-21-8-1087

Zhao, Y., Sundin, G. W., and Wang, D. (2009). Construction and analysis of pathogenicity island deletion mutants of Erwinia amylovora. Can. J. Microbiol. 55, 457-464. doi: 10.1139/W08-147

Conflict of Interest Statement: The author declares that the research was conducted in the absence of any commercial or financial relationships that could be construed as a potential conflict of interest.

Received: 07 January 2014; accepted: 11 March 2014; published online: 27 March 2014. Citation: Tampakaki AP (2014) Commonalities and differences of T3SSs in rhizobia and plant pathogenic bacteria. Front. Plant Sci. 5:114. doi: 10.3389/fpls.2014.00114 This article was submitted to Plant-Microbe Interaction, a section of the journal Frontiers in Plant Science.

Copyright (C) 2014 Tampakaki. This is an open-access article distributed under the terms of the Creative Commons Attribution License (CC BY). The use, distribution or reproduction in other forums is permitted, provided the original author(s) or licensor are credited and that the original publication in this journal is cited, in accordance with accepted academic practice. No use, distribution or reproduction is permitted which does not comply with these terms. 